\title{
Effect of Carbon Nanotubes Intensified Coolant on the Grinding Performance of Carburizing and Quenching 12Cr2Ni4A Steel
}

Gaofeng Zhang ( $\nabla$ zgfxu@xtu.edu.cn )

Xiangtan University https://orcid.org/0000-0001-8861-0214

Dejing Luo

Xiangtan University

Gaocan Wu

Xiangtan University

Da Liu

Xiangtan University

Jiakun Wang

Xiangtan University

Xin Deng

Xiangtan University

Jianbo Cai

Xiangtan University

\section{Research Article}

Keywords: 12Cr2Ni4A, Nanofluid, Carbon Nanotube, Grinding Force, Surface Roughness, Microhardness

Posted Date: May 18th, 2021

DOl: https://doi.org/10.21203/rs.3.rs-515974/v1

License: (9) (i) This work is licensed under a Creative Commons Attribution 4.0 International License. Read Full License

Version of Record: A version of this preprint was published at The International Journal of Advanced Manufacturing Technology on November 25th, 2021. See the published version at https://doi.org/10.1007/s00170-021-08160-6. 


\title{
Effect of carbon nanotubes intensified coolant on the grinding performance of carburizing and quenching 12Cr2Ni4A steel
}

\author{
Gaofeng Zhang ${ }^{\mathrm{a}}$, Dejing Luo ${ }^{\mathrm{b}}$, Gaocan Wu ${ }^{\mathrm{b}}$, Da Liu ${ }^{\mathrm{b}}$, Jiakun Wang ${ }^{\mathrm{b}}$, Xin Deng ${ }^{\mathrm{b}}$, Jianbo Cai ${ }^{\mathrm{b}}$ \\ ${ }^{a}$ Engineering Training Center, Xiangtan University, Xiangtan, 411105, Hunan, China \\ ${ }^{\mathrm{b} S c h o o l}$ of Mechanical Engineering, Xiangtan University, Xiangtan, 411105, Hunan, China \\ E-mail address: zgfxu@xtu.edu.cn
}

\begin{abstract}
$12 \mathrm{Cr} 2 \mathrm{Ni4A}$ steel is a high-quality alloy structural steel. This article explores the surface/sub-surface condition, surface roughness, and micromorphology of the workpiece surface after grinding $12 \mathrm{Cr} 2 \mathrm{Ni} 4 \mathrm{~A}$ steel via nanofluid casting to characterize the surface quality and analyzes the burn condition of the workpiece based on the microhardness of the cross-section of the workpiece and the micro-morphology of the subsurface of the workpiece. The test results indicate that the high heat transfer capacity of the carbon nanotube nanofluid can prevent the workpiece from being burned; further, the nanofluid casting type grinding obtains the lowest grinding force and surface roughness compared to the normal and tangential grinding forces. The surface roughness is reduced by $19.2 \%, 25.0 \%$, and $19.1 \%$ at the highest because the nanoparticles (carbon nanotubes) play a "lubricating effect" in the grinding area, and the surface quality of the workpiece is therefore improved. The microhardness of the cross-section of the workpiece indicates that a softened layer appears on the workpiece after dry grinding at normal temperature and on the workpiece after traditional casting grinding. The maximum softening layer thickness for normal temperature dry grinding and traditional casting grinding is $\sim 100$ and $40 \mu \mathrm{m}$, respectively; no obvious softening layer was observed in nanofluid casting grinding. Tempering burns and secondary quenching burns appear on the subsurface of the workpieces of normal temperature dry grinding and traditional casting grinding. The thicknesses of the affected layers of the tempering and secondary quenching burns are $\sim 98$ and $35 \mu \mathrm{m}$, respectively; for the nanofluid casting, no obvious burns were observed on the sub-surface of the workpiece ground by type grinding. Thus, this research aims to explore how to minimize grinding burns and propose a new type of nanofluid casting grinding technology.
\end{abstract}

Keywords : $12 \mathrm{Cr} 2 \mathrm{Ni4A}$; Nanofluid; Carbon Nanotube; Grinding Force; Surface Roughness;

Microhardness;

\section{Introduction}

Grinding technology is the most effective method to achieve precision machining in the field of mechanical manufacturing. Grinding is widely used because of its advantages of high precision, good surface quality, and wide adaptability [1]. Grinding is mostly used to machine difficult to machine materials [2]. However, in the process of grinding, the energy of the grinding interface is transformed into grinding heat, which is transmitted to the workpiece; this energy then causes a rapid increase in the temperature of the contact area between the workpiece and the grinding 
wheel, which results in the retempering of the workpiece surface, occurrence of burns [3], and a decrease in the physical properties of the workpiece surface [4]. For example, important industrial materials such as bearing steel, alloy structural steel, and ultra-high-strength steel easily burn during the grinding process, and the degree of the grinding burn considerably affects the service performance and service life of the metal parts. When the grinding conditions are not met, the temperature of the workpiece in the grinding zone increases beyond the tempering temperature of the workpiece material, which lead to grinding burns that cause tempering and microstructure changes on the surface and subsurface of the workpiece, Further, it can lead to a decrease in hardness and strength [5], and it may introduce unfavorable residual stress [6]. Javaroni et al.[7] reported that heat generated in the grinding zone is transferred between the grinding wheel, workpiece, coolant, and grinding debris. The grinding process focuses on the heat generated in the grinding zone to reduce the thermal damage on the surface of the processed workpiece. Pande and Lal [8] said that a higher specific energy demand in grinding can lead to higher heat generation, which results in a higher grinding zone temperature; this can adversely affect the quality of grinding products, which lead to the increased wear of the grinding wheels. Therefore, it is necessary to use coolants and lubricants to reduce the grinding temperature and the transfer of grinding heat to the workpiece [9]; further, reducing the transfer of the grinding heat to the workpiece will improve the quality of the machined surface [10]. To overcome these complications, researchers have attempted different cooling techniques over the years. A large-capacity pouring cooling delivery system or a high-pressure coolant delivery system is used to reduce the temperature of the grinding area and help reduce the tangential grinding force. In most mechanical processing, a conveying, cooling, and pouring system can meet the requirements of lowering the temperature; this system is effective for middle and low speed processing. Paul et al. [11]Compared with dry processing, traditional casting processing reduces the temperature of the core area by pouring a large amount of coolant on each cutting area, and this can increase the processing speed by $30-40 \%$ [12]. Bhatt et al. [13]showed that water has high heat and excellent cooling capacities. However, nanoparticles (such as carbon nanotubes) have good thermal conductivity, and carbon nanotube nanoparticles have good anti-wear and anti-friction properties; adding carbon nanotubes (CNTs) in the water to prepare nanofluids during grinding Identifying whether the workpiece has an enhanced cooling effect which can reduce grinding burns or whether the good anti-wear and anti-friction performance of nanoparticle carbon nanotubes can improve the surface quality of the workpiece has potential advantages.

$12 \mathrm{Cr} 2 \mathrm{Ni4} \mathrm{A}$ steel is a high-quality alloy structural steel and it has good strength, toughness, and hardenability. After carburizing and quenching, the hardness and wear resistance of the surface layer are found to be relatively high. Further, it is suitable for alternating stress and use in high-load environments such as gears, shafts, worm gears, and worms. However, 12Cr2Ni4A steel suffers from grind burn during the grinding process after carburizing and quenching. This paper proposes a method of casting grinding with a nanofluid to grind $12 \mathrm{Cr} 2 \mathrm{Ni} 4 \mathrm{~A}$ steel to reduce the grinding burn; further, the results of the method are compared with those of normal temperature dry grinding and traditional casting grinding. The thesis characterizes the surface quality after analyzing the roughness of the workpiece's surfa ce and the micro morphology of the workpiece surface, and characterize the burn condition of the workpiece by the microhardness of the cross section of the workpiece and the subsurface micro $\mathrm{m}$ orphology of the workpiece. 


\section{Experimental procedure}

\subsection{Workpiece materials}

The workpiece material is alloy structural steel (Grade: 12Cr2Ni4A, Workpiece size: $20 \mathrm{~mm}$ $\times 20 \mathrm{~mm} \times 20 \mathrm{~mm}$ ) with a chemical composition of alloy structural steel. The results of the heat treatment method are summarized in Tables 1 and 2. Figure 1 shows the microstructure of $12 \mathrm{Cr} 2 \mathrm{Ni} 4 \mathrm{~A}$ steel. A significant difference is observed in the metallographic structure between the carburized heat treatment and the uncarburized metallographic structure. For example, the metallographic structure of the carburized area is an acicular martensite, and the metallographic structure of the non-carburized area is lamellar martensite.

Table 1. 12Cr2Ni4A steel chemical elements and weight (\%).

\begin{tabular}{cccccccccc}
\hline Element & $\mathrm{C}$ & $\mathrm{Cr}$ & $\mathrm{Ni}$ & $\mathrm{Mn}$ & $\mathrm{Si}$ & $\mathrm{S}$ & $\mathrm{P}$ & $\mathrm{Cu}$ & $\mathrm{Fe}$ \\
\hline wt.\% & $0.10-0.16$ & $1.25-1.65$ & $3.25-3.65$ & $0.30-0.60$ & $0.17-0.37$ & $\leq 0.035$ & $\leq 0.035$ & $\leq 0.030$ & $\mathrm{Bal}$ \\
\hline
\end{tabular}

Table 2. Heat treatment process of $12 \mathrm{Cr} 2 \mathrm{Ni} 4 \mathrm{~A}$ steel.

\begin{tabular}{cr}
\hline Code & Heat treatment process \\
\hline \multirow{2}{*}{$12 \mathrm{Cr} 2 \mathrm{Ni} 4 \mathrm{~A}$} & Carburizing process temperature $925^{\circ} \mathrm{C} \times 20 \mathrm{~h}$, primary quenching $850^{\circ} \mathrm{C} \times 5 \mathrm{~h}$, high-temperature tempering \\
& $610^{\circ} \mathrm{C} \times 8 \mathrm{~h}$, secondary quenching $780^{\circ} \mathrm{C} \times 5 \mathrm{~h}$, and low-temperature tempering $200^{\circ} \mathrm{C} \times 10 \mathrm{~h}$. \\
\hline
\end{tabular}
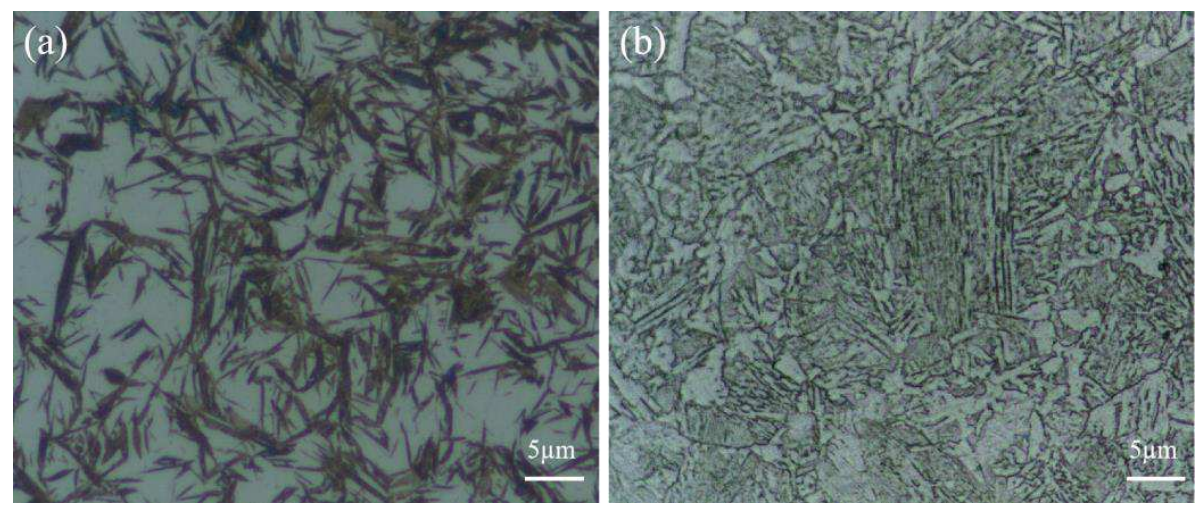

Fig. 1. Microstructure of 12Cr2Ni4A steel includes (a) carburized and (b) non-carburized areas.

\subsection{Grinding tests and measurement}

The grinding test was performed using a MGK7120X60 high-precision surface grinder (Hangzhou Machine Tool Factory). The grinding direction of the wheel is opposite to the moving direction of the worktable, i.e., the back grinding method. Before grinding, the grinding wheel is dressed by a single diamond dresser to ensure that the grinding state of the grinding wheel is the same every time. In the grinding process, the linear speed of the grinding wheel is fixed at $30 \mathrm{~m} / \mathrm{s}$, and the detailed grinding conditions are summarized in Table 3 .

Table 3. Grinding wheel, grinding test, and grinding wheel dressing parameters. 


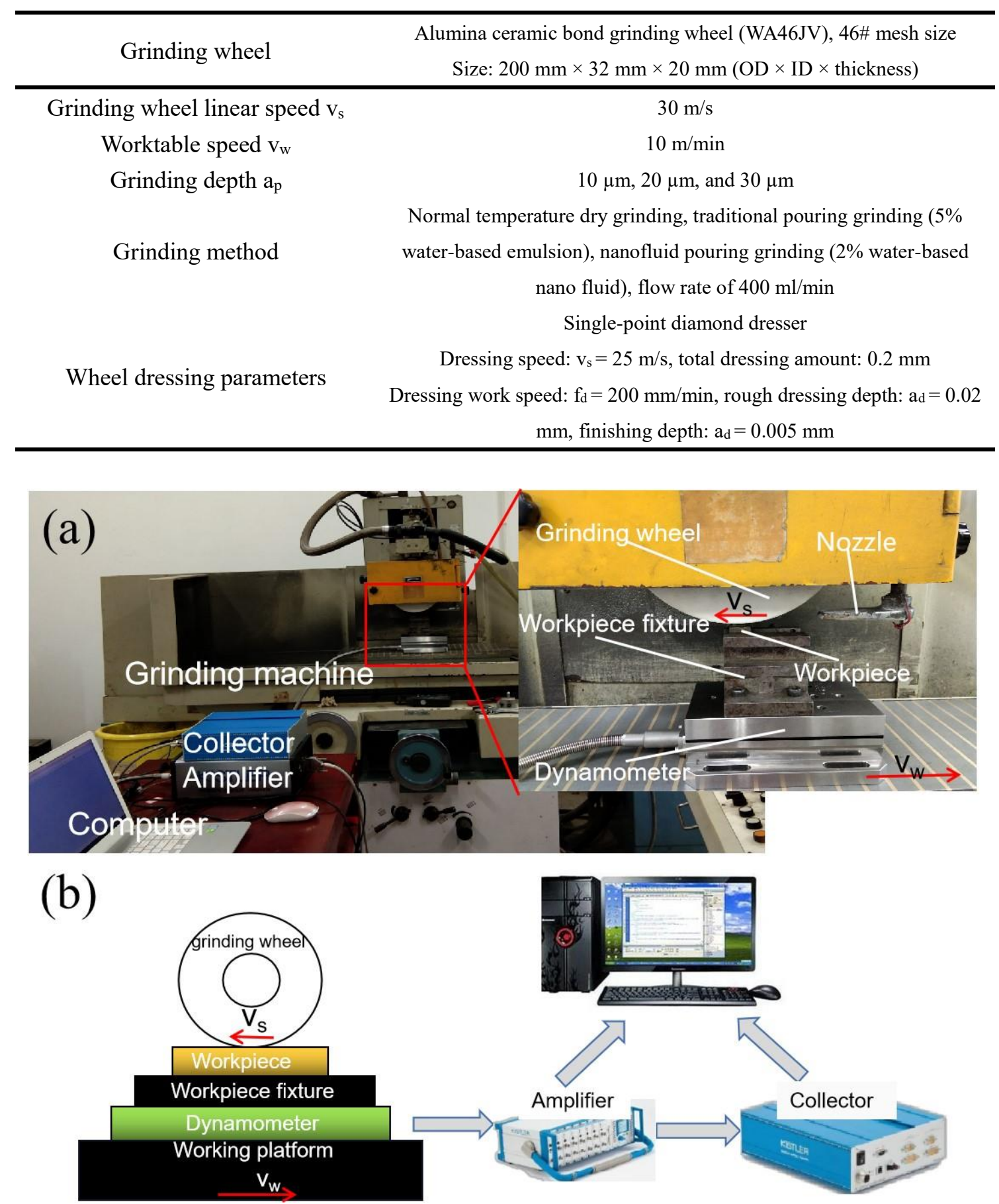

Fig. 2. (a) Experimental device, (b) schematic of grinding force measurement.

The experimental setup and schematic diagram for the grinding force measurement on $12 \mathrm{Cr} 2 \mathrm{Ni4}$ A steel are shown in detail in Fig. 2. After grinding, we first measure the surface roughness of the ground surface of the ground workpiece and use a scanning electron microscope to observe the ground surface. Then, a wire cutting machine is used to grind the workpiece along the grinding direction and vertically. Further, cut in the cutting direction, and manually polish the sample; then, use a polishing machine to polish the polished surface of the workpiece to achieve a mirror effect. When the polished surface of the workpiece is observed under an optical microscope, it has fewer scratches, no surface defects, and no thermal damage. The TMHV 1000Z hardness tester measures the microhardness of the samples using a Vickers indenter to apply a load of 200 
$\mathrm{N}$ and to hold the pressure for $10 \mathrm{~s}$. A metallographic corrosion solution containing $4 \mathrm{ml} \mathrm{HNO}_{3}+$ $96 \mathrm{ml} \mathrm{C}_{2} \mathrm{H}_{6} \mathrm{O}$ was prepared to corrode a polished workpiece sample of $12 \mathrm{Cr} 2 \mathrm{Ni} 4 \mathrm{~A}$ alloy structural steel for $10 \mathrm{~s}$. The metallographic and subsurface analyses were carried out by optical microscope and scanning electron microscope.

\subsection{Preparation of nanofluids}

The preparation of nanofluids employs two steps [14]; the process flow is shown in Fig. 3 (a). Multiwall carbon nanotubes (MWCNTs) were purchased from Shenzhen suiheng Technology Co., Ltd. with a purity of over 97\%; the diameter of the MWCNTs was between 3 and $15 \mathrm{~nm}$, and the pipe length was between 15 and $30 \mu \mathrm{m}$. The scanning electron microscope is shown in Figure 3(b). Because of the small size and large specific surface area of the MWCNTs, there is a strong van der Waals force between the CNTs, and therefore, tangles often occur and form large particles, which weaken the stability of MWNTs in water [15]. First, the MWCNTs were dispersed by the wet grinding process, and the dispersed MWCNTs were filtered and dried. After adding a proper amount of MWCNTs $(2.0 \% \mathrm{wt})$ into deionized water and adding polyvinylpyrrolidone (PVP), a nonionic dispersant with half of the content of MWCNTs, i.e., the water-based nano fluid pouring liquid, was prepared by ultrasonic vibration equipment for $40 \mathrm{~min}$.

(a)

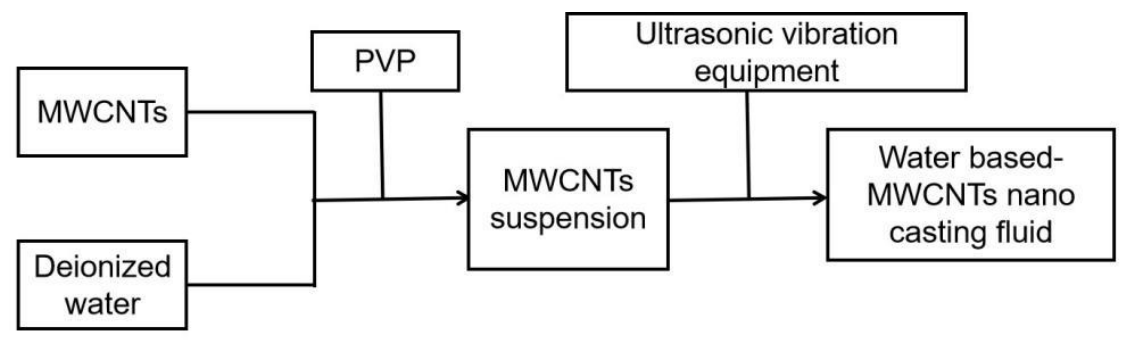

(b)

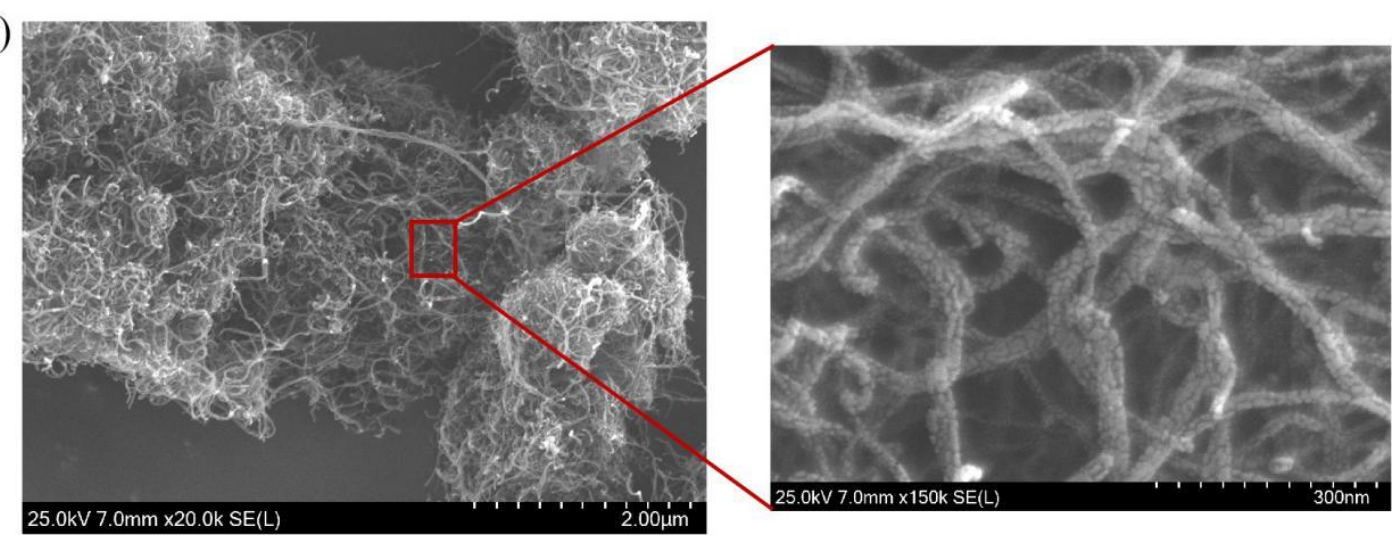

Fig. 3. (a) Process flow chart of water-based nanofluid; (b) SEM image of MWCNTs.

\section{Results and discussion}

\subsection{Grinding force and specific grinding energy}

Fig. 4 shows the different grinding methods for $12 \mathrm{Cr} 2 \mathrm{Ni} 4 \mathrm{~A}$ alloy structural steel (normal temperature dry grinding, traditional pouring grinding, and nanofluid pouring grinding), the grinding force $\mathrm{F}^{\prime}$ per unit grinding width, and the graph of grinding depth ap. Grinding 12Cr2Ni4A steel (normal grinding force $\mathrm{F}_{\mathrm{n}}^{\prime}$ and tangential grinding force $\mathrm{F}_{\mathfrak{t}}^{\prime}$ ) increases as the grinding depth 
increases. As shown in Figure 4(b), during the grinding process of the $12 \mathrm{Cr} 2 \mathrm{Ni} 4 \mathrm{~A}$ alloy structural steel, the normal temperature dry grinding force $F_{n}^{\prime}$ and $F_{t}^{\prime}$ increased from $3.6 \mathrm{~N} / \mathrm{mm}$ to 10.1 $\mathrm{N} / \mathrm{mm}$, and $1.2 \mathrm{~N} / \mathrm{mm}$ increased to $2.68 \mathrm{~N} / \mathrm{mm}$. The traditional casting grinding force $F_{n}^{\prime}$ and $F_{t}^{\prime}$ increased from $3.3 \mathrm{~N} / \mathrm{mm}$ to $9.7 \mathrm{~N} / \mathrm{mm}$ and from $1.04 \mathrm{~N} / \mathrm{mm}$ to $2.3 \mathrm{~N} / \mathrm{mm}$, respectively. The nanofluid casting grinding force $F_{n}^{\prime}$ and $F_{t}^{\prime}$ increase from $2.9 \mathrm{~N} / \mathrm{mm}$ to $9.0 \mathrm{~N} / \mathrm{mm}$ and from 0.71 $\mathrm{N} / \mathrm{mm}$ to $2.01 \mathrm{~N} / \mathrm{mm}$, respectively. When the grinding depth is $\mathrm{a}_{\mathrm{p}}=20 \mu \mathrm{m}$, the nanofluid casting grinding forces $\mathrm{F}_{\mathrm{n}}^{\prime}$ and $\mathrm{F}_{\mathrm{t}}^{\prime}$ are reduced by $12.1 \%$ and $16.7 \%$, respectively, compared with the traditional casting grinding forces $\mathrm{F}_{\mathrm{n}}^{\prime}$ and $\mathrm{F}_{\mathrm{t}}^{\prime}$; Compared with the normal temperature dry grinding forces $F_{n}^{\prime}$ and $F_{t}^{\prime}$, the casting grinding forces $F_{n}^{\prime}$ and $F_{t}^{\prime}$ are reduced by $19.2 \%$ and $25.0 \%$, respectively. When the grinding depth is $\mathrm{a}_{\mathrm{p}}=30 \mu \mathrm{m}$, the nanofluid casting grinding forces $\mathrm{F}_{n}{ }_{n}$ and $\mathrm{F}_{\mathrm{t}}^{\prime}$ are reduced by $7.2 \%$ and $12.6 \%$, respectively, compared with the traditional casting grinding forces $F_{n}^{\prime}$ and $F_{t}^{\prime}$. Compared with normal temperature dry grinding forces $F_{n}^{\prime}$ and $F_{t}^{\prime}$, the casting grinding forces $\mathrm{F}_{\mathrm{n}}^{\prime}$ and $\mathrm{F}_{\mathrm{t}}^{\prime}$ are reduced by $10.9 \%$ and $22.1 \%$, respectively.
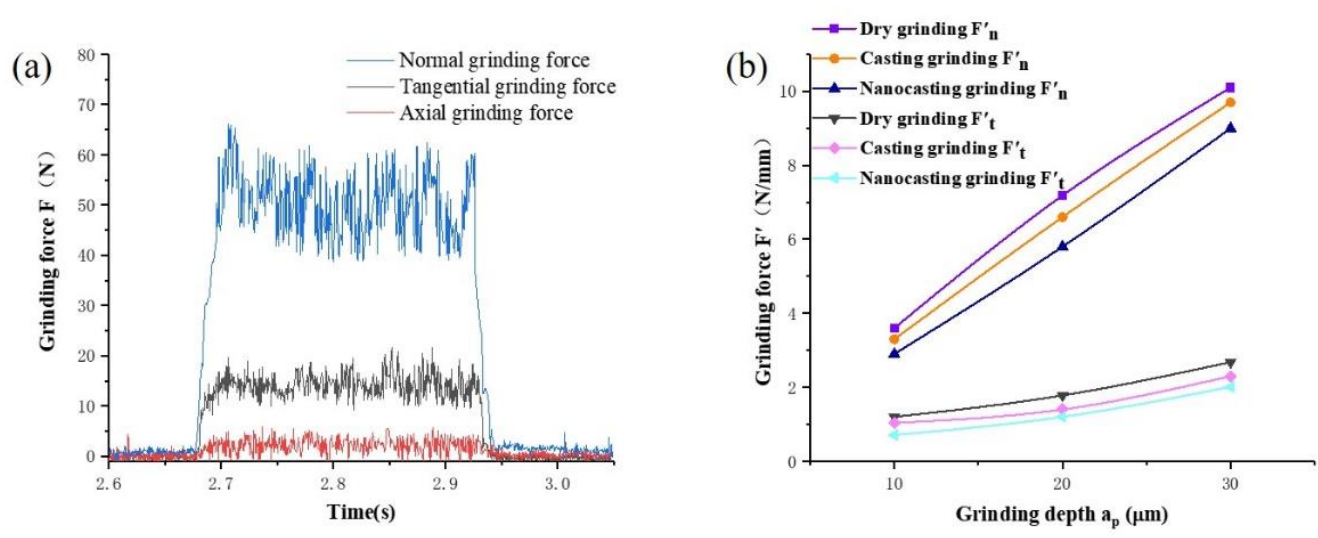

Fig. 4. (a) Grinding force measured by nanofluid pouring grinding $\left(\mathrm{v}_{\mathrm{s}}=30 \mathrm{~m} / \mathrm{s}, \mathrm{v}_{\mathrm{w}}=10\right.$ $\left.\mathrm{m} / \mathrm{min}, a_{\mathrm{p}}=10 \mu \mathrm{m}\right)$; (b) Grinding force per unit width $\mathrm{F}^{\prime}$ varies with grinding depth $\mathrm{a}_{\mathrm{p}}$.

Using the tangential grinding force in Figure 4, the specific grinding energy $E_{e}$ can be calculated as

$$
\begin{gathered}
F_{t}^{\prime}=\frac{F_{\mathrm{t}}}{b} \\
E_{\mathrm{e}}=\frac{\mathrm{F}_{\mathrm{t}} \mathrm{v}_{\mathrm{s}}}{\mathrm{v}_{\mathrm{w}} \mathrm{a}_{\mathrm{p}} \mathrm{b}}=\frac{F_{t}^{\prime} v_{s}}{v_{w} a_{p}}
\end{gathered}
$$

Further, the maximum undeformed chip thickness $\mathrm{h}_{\mathrm{gmax}}$ can be calculated according to

$$
\mathrm{h}_{g \max }=\left[\frac{6}{C r}\left(\frac{v_{w}}{v_{s}}\right)\left(\frac{a_{p}}{d_{s}}\right)^{\frac{1}{2}}\right]^{\frac{1}{2}}
$$

where $\mathrm{C}$ denotes the average number of effective abrasive particles per unit area $\left(\mathrm{C}=3.5 \mathrm{~mm}^{-2}\right.$ in the current study); $r$ denotes the ratio of the width to the thickness on the section, $r=2 \tan \gamma, \gamma$ denotes half of the apex angle of the abrasive particles. Equation (2) indicates that when the grinding parameters are the same during the grinding process, there is a positive correlation between $\mathrm{E}_{\mathrm{e}}$ and $\mathrm{F}_{\mathrm{t}}^{\prime}$. 
Further, $Z^{\prime}$ w can be calculated as

$$
\mathrm{Z}^{\prime}{ }_{\mathrm{w}}=\mathrm{a}_{\mathrm{p}} \mathrm{V}_{\mathrm{w}}
$$
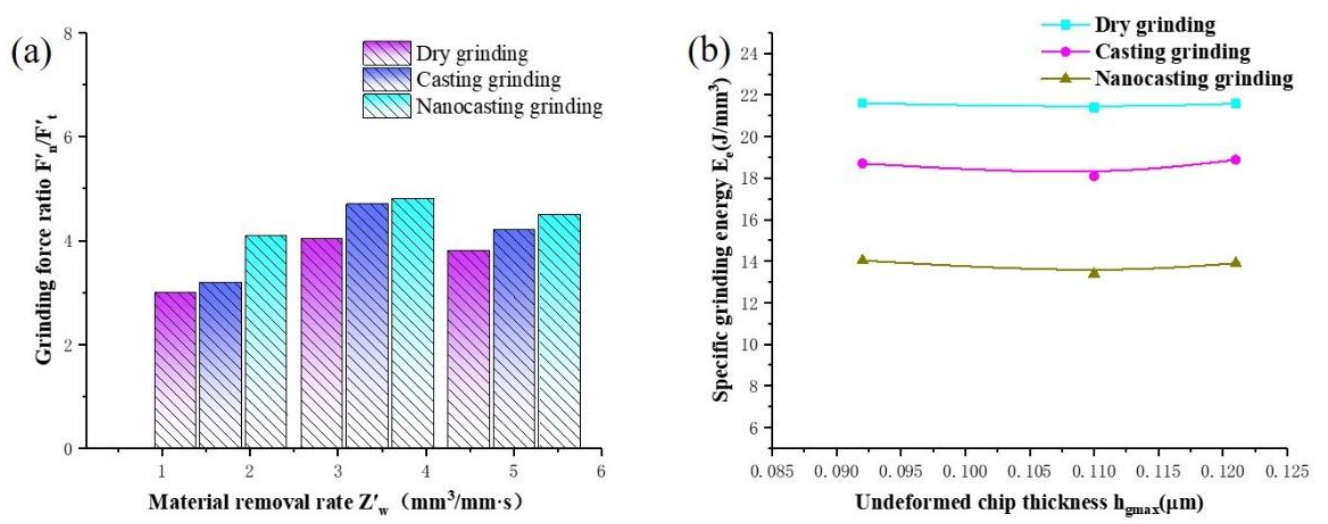

Fig. 5. (a) The force ratio changes with the material removal rate; (b) specific grinding energy change with the maximum undeformed chip thickness.

Figure 5(a) indicates that as $Z_{w}^{\prime}$ (different grinding depths, $Z_{w}^{\prime}$ is $1.67 \mathrm{~mm}^{3} / \mathrm{mm} \cdot \mathrm{s}, 3.34 \mathrm{~mm} / \mathrm{mm} \cdot \mathrm{s}$, and $5.01 \mathrm{~mm} / \mathrm{mm} \cdot \mathrm{s}$ ) increases, the grinding force compared with $F_{n}^{\prime}$ and $F_{t}^{\prime}$ first increases and then decreases. Under normal temperature dry grinding, the grinding force ratio $\mathrm{F} \mathrm{n}^{\prime} / \mathrm{F} \mathrm{t}$ ranges between 3.0 and 4.05 at different material removal rates. Under the traditional pouring grinding method, the grinding force ratio $\mathrm{F}_{\mathrm{n}}{ } / \mathrm{F}_{\mathrm{t}} \mathrm{t}$ ranges between 3.2 and 4.7 at different material removal rates. Under the nanofluid pouring grinding method, the grinding force ratio is at different material removal rates. The range of $\mathrm{F}_{n}^{\prime} / \mathrm{F}_{\mathrm{t}}^{\prime}$ is 4.1-4.8. According to reports, increasing the material removal rate will result in greater grinding load, an increase in the wear of the grinding wheel, and an increase in the force ratio [16]. However, in the current research, the observed force ratio $\mathrm{F}_{\mathrm{n}}{ }^{\prime} \mathrm{F}_{\mathrm{t}}{ }_{\mathrm{t}}$ and $Z^{\prime}{ }_{\mathrm{w}}$ tend to increase first and then decrease. When $Z^{\prime}{ }_{\mathrm{w}}$ is $3.34 \mathrm{~mm} / \mathrm{mm} \cdot \mathrm{s}$, the force ratio is the largest. Godino et al. [17]studied the wear behavior of alumina grinding wheels under different grinding conditions; this scenario can be attributed to the shedding of abrasive particles and the self-sharpening effect of the alumina grinding wheel caused by the fracture of abrasive particles [18]. Figure 5(b) shows the change in the specific grinding energy $E_{e}$ with respect to the maximum

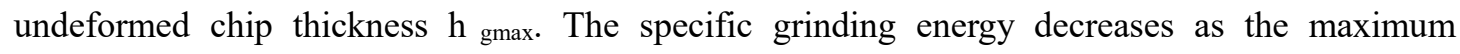
undeformed chip thickness $h_{\text {gmax }}$ increases. Three different lubrication conditions, i.e., the maximum undeformed chip thickness $h_{\text {gmax }}$ in the range of $0.092-0.121 \mu \mathrm{m}$; the specific grinding energy $E_{e}$ of normal temperature dry grinding is in the range of 21.4-21.6 J/mm $\mathrm{mm}^{3}$. The range of the grinding energy $E_{e}$ is $18.08-18.88 \mathrm{~J} / \mathrm{mm} 3$; the range of the specific grinding energy $E_{e}$ for the nanofluid pouring grinding is $13.4-14.03 \mathrm{~J} / \mathrm{mm} 3$. Ghosh et al. [19] and Li et al. [20]observed that, in the grinding process, $\mathrm{E}_{\mathrm{e}}$ is composed of friction energy and chip formation energy. However, most grinding energy is converted into heat [21]; for any grinding parameter, the friction energy accounts for more than $50 \%$ of the total grinding energy [22]. Combining the results of Figure 5 (b), it can be inferred that $12 \mathrm{Cr} 2 \mathrm{Ni4A}$ steel has the highest frictional energy during dry grinding at room temperature, and the smallest frictional energy during nanofluid pouring grinding; especially when $h_{\text {gmax }}=0.092 \mu \mathrm{m}$. Compared with normal temperature dry grinding, the specific grinding energy $E_{e}$ of nanofluid casting grinding is reduced by $35.04 \%$; the specific grinding 
energy $E_{e}$ of nanofluid casting grinding, by $25.0 \%$ compared with the traditional casting grinding.

\subsection{Surface roughness and surface morphology}

Fig. 6 shows the comparison of the surface roughness of the workpieces with three different grinding depths obtained using three different grinding methods. The surface roughness of the workpiece is measured three times for each workpiece, and the measured surface roughness value is averaged. In the grinding process, when the grinding depth is $\mathrm{a}_{\mathrm{p}}=10 \mu \mathrm{m}$, it is found that the surface roughness of the nanofluid cast grinding workpiece is $19.1 \%$ lower than that of the normal temperature dry grinding workpiece when the grinding depth is $a_{p}=30 \mu \mathrm{m}$. This implies that the surface roughness of the nanofluid casting grinding workpiece is $9.4 \%$ lower than that of the normal temperature dry grinding workpiece; thus, when the grinding depth is $\mathrm{a}_{\mathrm{p}}=30 \mu \mathrm{m}$, it is for the surface roughness of the nanofluid casting grinding workpiece. The surface roughness of the workpiece is reduced by $11.5 \%$ compared with the normal temperature dry grinding. Observing the change in the surface roughness of the workpiece indicates that the surface roughness of nanofluid pouring grinding, normal temperature dry grinding and traditional pouring grinding show similar trends at different grinding depths. In addition, Figure 6 indicates that, at different grinding depths, the surface roughness of the workpieces of nanofluid casting grinding is lower than that of normal temperature dry grinding and traditional casting grinding. The fluid casting grinding obtains the minimum surface roughness and the room temperature dry grinding obtains the maximum surface roughness.

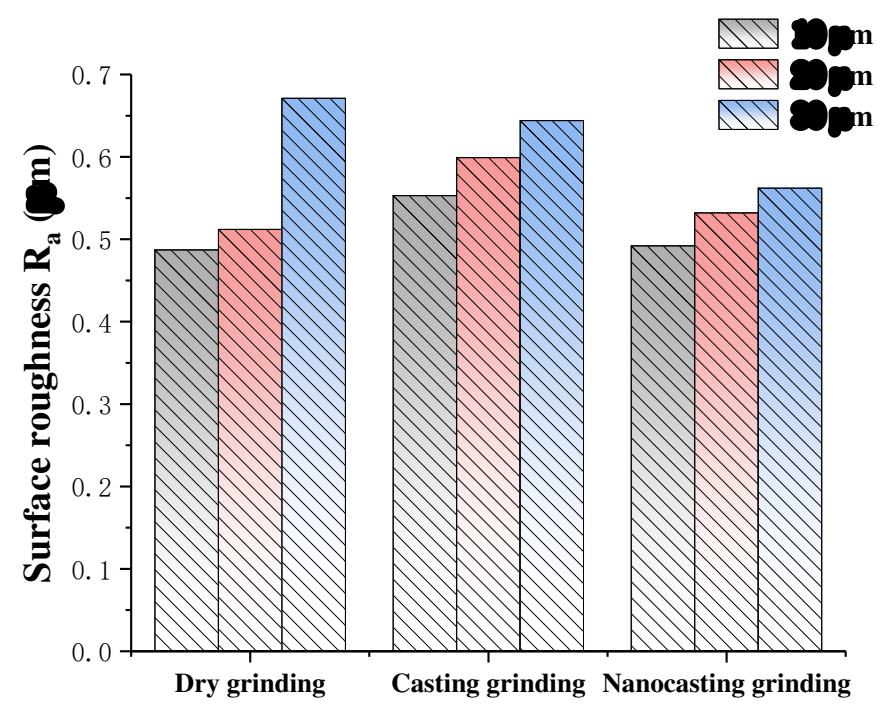

Fig. 6. Surface roughness of workpieces with different grinding depths in three different grinding methods.

As shown in Fig. 7, the scanning electron microscope observes the surface morphology of the workpiece surface after grinding the $12 \mathrm{Cr} 2 \mathrm{Ni} 4 \mathrm{~A}$ alloy steel. When the grinding depth $\mathrm{a}_{\mathrm{p}}=20 \mu \mathrm{m}$, as shown in Figure 7(a)(b)(c), the surface of the nanofluid casting grinding is better than that of normal temperature dry grinding and traditional casting grinding. There are many surface defects on the machining surface of the type grinding including overlaps of the workpiece material, tearing of the workpiece material, and adhesion of metal fragments. The machining surface defects for the traditional casting grinding are less than those of the normal temperature dry grinding and 
only nanofluid casting grinding. The machined surface defects of the grinding are the least; when the grinding depth $a_{p}=30 \mu \mathrm{m}$, the machined surface is deteriorated as shown in Figure 7(d)(e)(f); the machined surface defects of normal temperature dry grinding such as the workpiece material overlap, surface cavities, tearing of workpiece material, and adhesion of metal fragments among the problem of the workpiece material overlap and the adhesion of metal fragments is the most serious through the comparison of Figures 7 (d), (e), and (f). The machined surface of pouring grinding is better than that of normal temperature dry grinding and traditional pouring grinding. The detailed analysis is as follows: (1) In the grinding process, the abrasive particles fall off or the abrasive particles break to form new cutting edges, which lead to different abrasive scratches on the surface of the workpiece. (2) Grinding during dry grinding at room temperature increases the temperature at grinding to be too high, which causes the workpiece material to overlap and a large number of metal fragments to adhere to the workpiece. (3) The grinding moment temperatures of traditional pouring grinding and nanofluid pouring grinding are not as high as that of normal temperature dry grinding. The defects on the surface of the workpiece are relatively few.
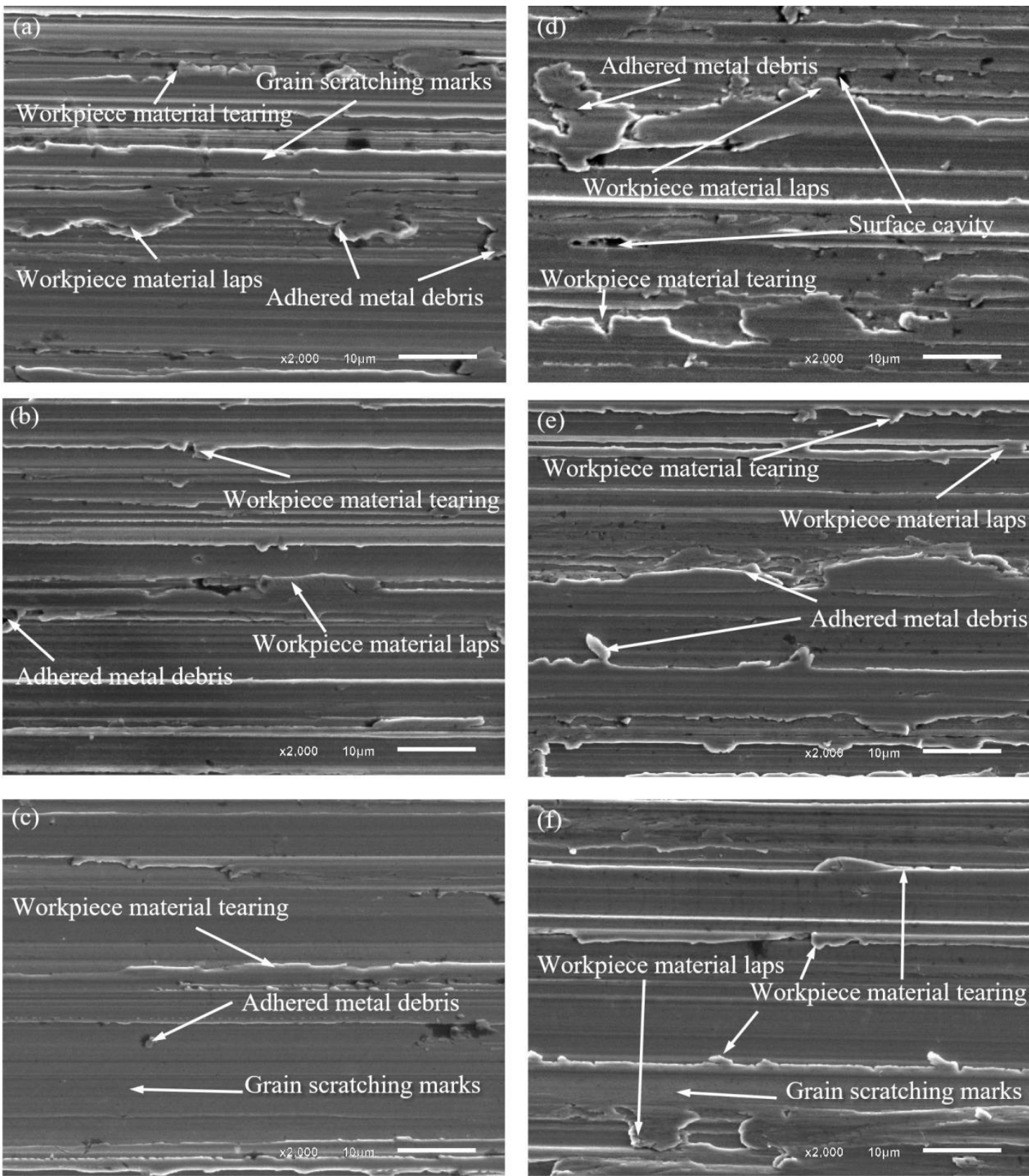
Fig. 7. SEM image of the machined surface. (a) Dry grinding at room temperature, (b) Traditional pouring grinding, (c) Nanofluid pouring grinding $\left(\mathrm{v}_{\mathrm{s}}=30 \mathrm{~m} / \mathrm{s}, \mathrm{v}_{\mathrm{w}}=10 \mathrm{~m} / \mathrm{min}, \mathrm{a}_{\mathrm{p}}=20 \mu \mathrm{m}\right)$ and (d) normal temperature dry grinding, (e) traditional pouring grinding, (f) nanofluid pouring grinding $\left(\mathrm{v}_{\mathrm{s}}=30 \mathrm{~m} / \mathrm{s}, \mathrm{v}_{\mathrm{w}}=10 \mathrm{~m} / \mathrm{min}, \mathrm{a}_{\mathrm{p}}=30 \mu \mathrm{m}\right)$.

\subsection{Microhardness and subsurface microstructure on workpiece}

\section{cross-section}

Fig. 8 shows the distribution of the microhardness depth measured perpendicular to the feed direction under three different grinding methods and grinding depths in the grinding test. At different grinding depths, the grinding surfaces of nanofluid and traditional pouring grinding are surface hardened, and the grinding surface of normal temperature dry grinding is softened to different degrees (Fig. 8(c)). When the grinding depth $\mathrm{a}_{\mathrm{p}}=30 \mu \mathrm{m}$, the maximum Vickers hardness of the traditional pouring grinding is as high as $841 \mathrm{HV}(16.7 \%$ higher than the carburized surface before grinding), and the hardness is rapidly reduced to $712 \mathrm{HV}$; then, the hardness rises to 757 $\mathrm{HV}$, and then, it slowly decreases until the hardness of the workpiece matrix. The reason for this phenomenon is that the instantaneous grinding temperature of the workpiece surface exceeds the critical temperature of the metal phase transition, and then, under the action of the coolant, secondary quenching burns appear at normal temperature. The ground surface hardness of dry grinding is $618 \mathrm{HV}$ lower than the unground workpiece surface hardness of $700 \mathrm{HV}$, and then, it rises to $688 \mathrm{HV}$; then, it slowly decreases until the workpiece matrix hardness. The reason for this phenomenon is that the instantaneous grinding temperature of the workpiece surface exceeds that of martensite. The volume transition temperature is lower than the metal phase transition critical temperature, and the cooling of the workpiece is slow; therefore, the surface hardness after grinding decreases. The thermal softening of the workpiece material is attributed to the effect of thermal energy on the mechanical plastic deformation [23]; therefore, as shown in Figure 8(c), when the grinding depth $a_{p}=30 \mu \mathrm{m}$, the softening layer of the traditional casting grinding workpiece is about $40 \mu \mathrm{m}$ for the normal temperature dry type. The softening layer of the grinding workpiece is about $100 \mu \mathrm{m}$ (Fig. 8(b)). When the grinding depth $\mathrm{a}_{\mathrm{p}}=20 \mu \mathrm{m}$, the softening layer of the traditional casting type grinding workpiece is about $15 \mu \mathrm{m}$, and the softening layer of the normal temperature dry grinding workpiece is $\sim 20 \mu \mathrm{m}$. Figure 8 (a) shows that, at the grinding depth $\mathrm{a}_{\mathrm{p}}=10 \mu \mathrm{m}$, the thickness of the softened layer cannot be assessed. 
(a)

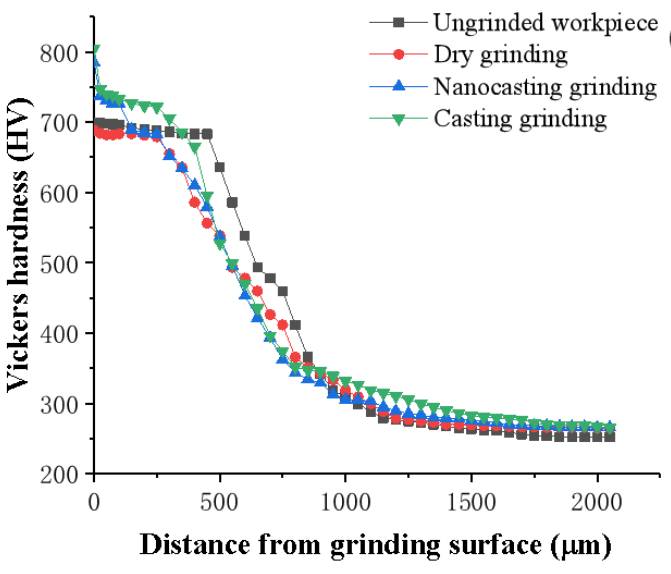

(c)

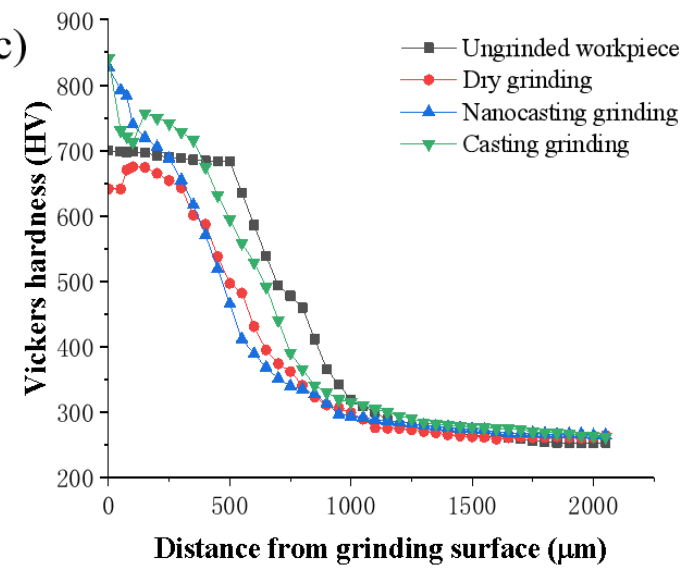

Fig. 8. Microhardness change of the cross section of the workpiece; (a) $\mathrm{v}_{\mathrm{s}}=30 \mathrm{~m} / \mathrm{s}, \mathrm{v}_{\mathrm{w}}=10 \mathrm{~m} / \mathrm{min}$, $a_{p}=10 \mu \mathrm{m},(b) v_{s}=30 \mathrm{~m} / \mathrm{s}, v_{w}=10 \mathrm{~m} / \mathrm{min}, a_{p}=20 \mu \mathrm{m}$, (c) $v_{s}=30 \mathrm{~m} / \mathrm{s}, v_{w}=10 \mu / m i n, a_{p}=30$ $\mu \mathrm{m}$. 
(a)

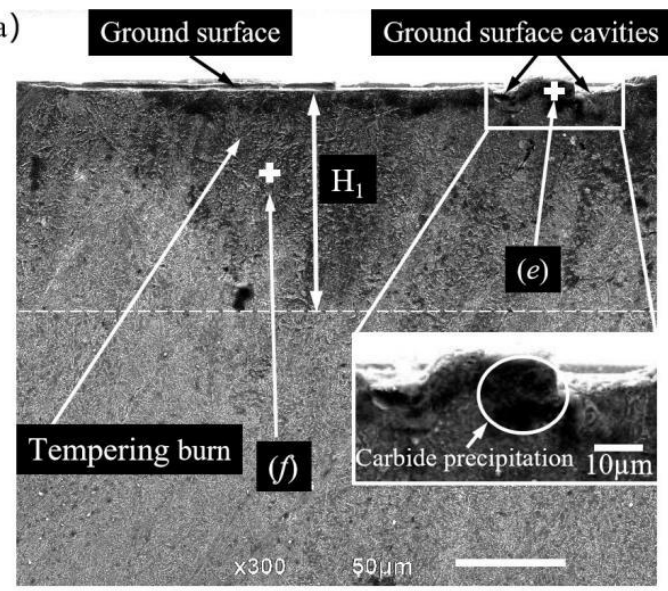

(c)

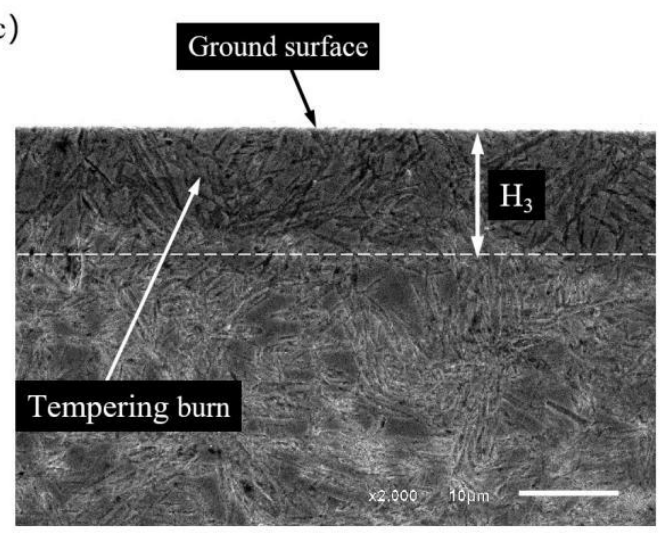

(e)

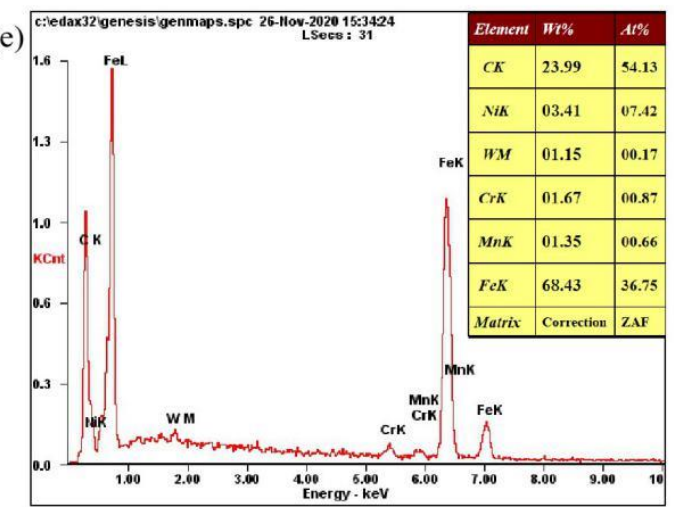

(b) Ground surface Ground surface cavities

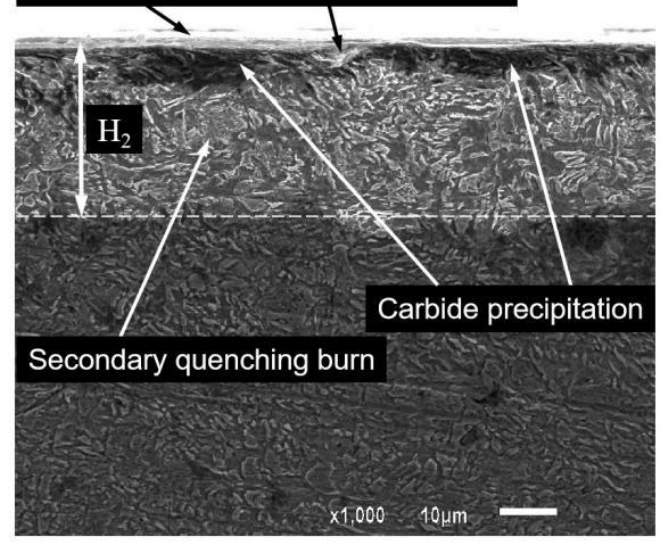

(d)

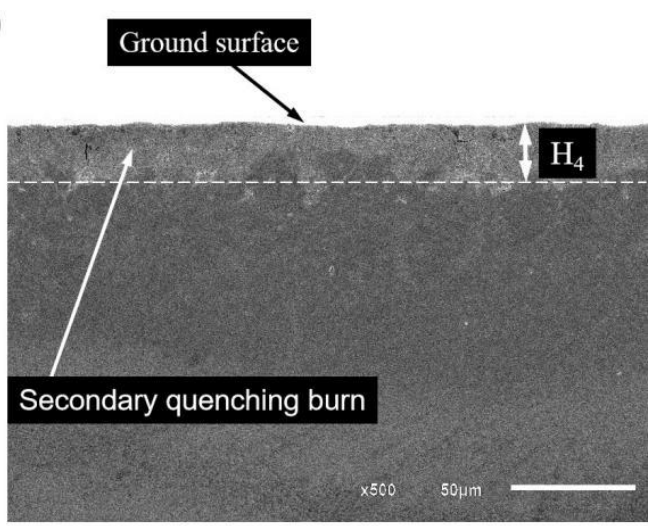

(f)

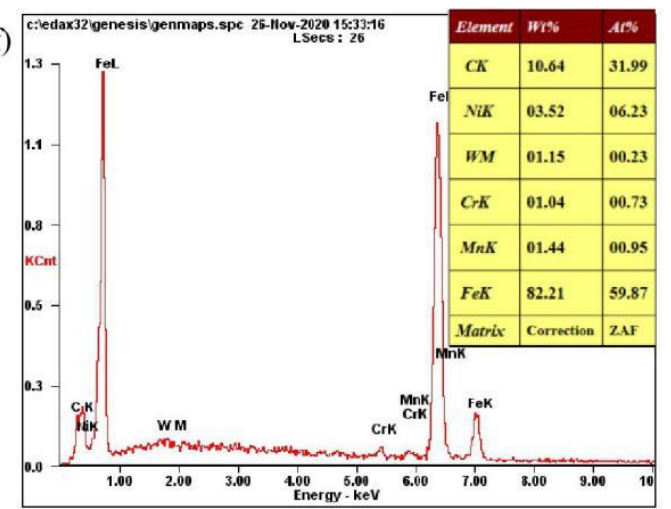

Fig. 9. Scanning electron micrograph and energy spectrum of the subsurface of the workpiece (a) Dry grinding at room temperature $\left(\mathrm{v}_{\mathrm{s}}=30 \mathrm{~m} / \mathrm{s}, \mathrm{v}_{\mathrm{w}}=10 \mathrm{~m} / \mathrm{min}, \mathrm{a}_{\mathrm{p}}=30 \mu \mathrm{m}\right)$, (b) Traditional pouring grinding $\left(\mathrm{v}_{\mathrm{s}}=30 \mathrm{~m} / \mathrm{s}, \mathrm{v}_{\mathrm{w}}=10 \mathrm{~m} / \mathrm{min}, \mathrm{a}_{\mathrm{p}}=30 \mu \mathrm{m}\right)$, (c) Dry grinding at room temperature $\left(v_{\mathrm{s}}=30 \mathrm{~m} / \mathrm{s}, \mathrm{v}_{\mathrm{w}}=10 \mathrm{~m} / \mathrm{min}, \mathrm{a}_{\mathrm{p}}=20 \mu \mathrm{m}\right)$, (d) Traditional pouring grinding $\left(\mathrm{v}_{\mathrm{s}}=30 \mathrm{~m} / \mathrm{s}, \mathrm{v}_{\mathrm{w}}=10\right.$ $\mathrm{m} / \mathrm{min}, \mathrm{a}_{\mathrm{p}}=20 \mu \mathrm{m}$ ), (e) Point $e$ energy spectrum, (f) Point $f$ energy spectrum.

Fig. 9 shows the scanning electron microscope images of the subsurface using alumina grinding wheels under different lubrication conditions and different grinding depths. Subsurface defects (cavities) are found when the grinding depth $a_{p}=30 \mu \mathrm{m}$ for dry grinding at room temperature. The subsurface of the cut workpiece has tempered burns, and the layer thickness $\mathrm{H}_{1}$ of the tempered burns is $\sim 98 \mu \mathrm{m}$; the subsurface of the traditional casting grinding has secondary quenching burns, and the layer thickness of the secondary quenching burns $\mathrm{H}_{2}$ is $\sim 35 \mu \mathrm{m}$. When 
the grinding depth is $a_{p}=20 \mu \mathrm{m}$, tempering burns appear on the subsurface of the workpiece under normal temperature dry grinding, and the layer thickness $\mathrm{H}_{3}$ of the tempering burns is about 10 $\mu \mathrm{m}$. The subsurface of the traditional casting grinding has secondary quenching burns. The layer thickness $\mathrm{H}_{4}$ of the second quenching burn is $\sim 15 \mu \mathrm{m}$. At the room temperature dry grinding depth $\mathrm{a}_{\mathrm{p}}=30 \mu \mathrm{m}$, the carbides are precipitated. The energy spectrum (e) indicates that the carbon content is significantly greater than that in the energy spectrum (f).

\subsection{Calculation and analysis of grinding force}

Grinding force plays an important role in the grinding process because it not only directly affects the wear of the grinding wheel, grinding temperature, and surface integrity, but also has a considerable effect on the removal of materials [22]. However, the variables of this important and monitorable process largely depend on the grinding conditions and material properties. Therefore, it can be analyzed by burning the workpiece according to the grinding force. Both normal and tangential grinding forces are composed of chip forming force and friction force [21]. According to the grinding force model proposed by Lichun et al. [24] and Yao et al. [25] the grinding force component can be expressed as

$$
\begin{aligned}
& \left\{\begin{array}{l}
F_{\mathrm{n}}^{\prime}=F^{\prime}{ }_{n c}+F^{\prime}{ }_{n s} \\
F^{\prime}{ }_{t}=F^{\prime}{ }_{t c}+F^{\prime}{ }_{t s}
\end{array}\right. \\
& \left\{\begin{array}{l}
F_{\mathrm{nc}}^{\prime}=H \frac{v_{w}}{v_{s}} a_{p} \\
F_{n s}^{\prime}=\delta p A\left(c_{1}\right)^{\beta}\left(\frac{v_{w}}{v_{s}}\right)^{\alpha} \frac{d_{e}^{\frac{1-\alpha}{2}}}{1+\alpha} a_{p}^{\frac{1+\alpha}{2}}
\end{array}\right. \\
& \left\{\begin{array}{l}
F_{\mathrm{tc}}^{\prime}=\frac{\pi H}{4 \tan \gamma} \frac{v_{w}}{v_{s}} a_{p} \\
F_{t s}^{\prime}=\mu \delta p A\left(c_{1}\right)^{\beta}\left(\frac{v_{w}}{v_{s}}\right)^{\alpha} \frac{d_{e}^{\frac{1-\alpha}{2}}}{1+\alpha} a_{p}^{\frac{1+\alpha}{2}}
\end{array}\right.
\end{aligned}
$$

where $F_{n c}^{\prime}, F_{n s}^{\prime}, F_{t c}^{\prime}$, and $F_{\text {ts }}^{\prime}$ denote the normal tangent and tangential chip forming force components, normal tangential friction force, and tangential chip friction force components, respectively; $\mathrm{H}$ denotes the grinding force per unit area; $\delta$ represents the top area of a single working abrasive particle, i.e., the workpiece and the working grinding; the actual contact area of the grain $\mathrm{p}$ denotes the average contact pressure between the actual wear surface of the abrasive grain and the workpiece; A represents the proportional coefficient related to the number of static sharpening; $\alpha$ and $\beta$ represent the exponential coefficients related to the grain distribution;c1 denotes the static sharpening density; $\gamma$ denotes half of the tip angle of the abrasive particles (generally $\gamma=60$.); $\mu$ represents the friction coefficient; and $\mathrm{d}_{\mathrm{e}}$ represents the equivalent diameter of the grinding wheel. Since the state of the grinding wheel before grinding is the same, the 
exponential coefficients $\alpha$ and $\beta$ are equal. Equations (5), (6), and (7) can be written as

$$
\left\{\begin{array}{l}
F_{\mathrm{n}}^{\prime}=H_{1} \frac{v_{w}}{v_{s}} a_{p}+H_{2}\left(\frac{v_{w}}{v_{s}}\right)^{\alpha} \frac{d_{e}^{\frac{1-\alpha}{2}}}{1+\alpha} a_{p}^{\frac{1+\alpha}{2}} \\
F_{\mathrm{t}}^{\prime}=H_{3} \frac{v_{w}}{v_{s}} a_{p}+H_{4}\left(\frac{v_{w}}{v_{s}}\right)^{\alpha} \frac{d_{e}^{\frac{1-\alpha}{2}}}{1+\alpha} a_{p}^{\frac{1+\alpha}{2}}
\end{array}\right.
$$

where $H_{1}=H, \quad H_{2}=\delta p A\left(c_{1}\right)^{\beta}, H_{3}=\frac{\pi H}{4 \tan \gamma}$, and $H_{4}=\mu H_{2}$. The results of the normal temperature dry grinding force, traditional pouring grinding force, and nanofluid pouring grinding force (Fig. 4) are substituted into the equation, respectively, and coefficients $\mathrm{H}_{1}, \mathrm{H}_{2}, \mathrm{H}_{3}$, and $\mathrm{H}_{4}$ in equation (8) are calculated. $\mathrm{H}_{1}=1.4 \times 10^{3}, \mathrm{H}_{2}=3.2, \mathrm{H}_{3}=0.6 \times 10^{3}, \mathrm{H}_{4}=0.8 ; \mathrm{H}_{1}=5.8 \times 10^{3}, \mathrm{H}_{2}=$ 2.7, $\mathrm{H}_{3}=2.6 \times 10^{3}, \mathrm{H}_{4}=0.59$; and $\mathrm{H}_{1}=5.3 \times 10^{3}, \mathrm{H}_{2}=2.6, \mathrm{H}_{3}=2.3 \times 10^{3}, \mathrm{H}_{4}=0.54$.

The coefficients of $\mathrm{H}_{1}$ and $\mathrm{H}_{3}$ generated by chip formation are very large, which indicates that the size effect is very significant in the micro cutting process [23]. Coefficients $\mathrm{H}_{2}$ and $\mathrm{H}_{4}$ related to friction have relatively small changes, and $\mathrm{p}$ is consistent with coefficients $\mathrm{H}_{2}$ and $\mathrm{H}_{4}$.

Table 4. Test and calculated values of the normal and tangential grinding forces.

\begin{tabular}{|c|c|c|c|c|c|c|c|c|c|}
\hline Grinding method & $\begin{array}{c}\text { Wheel } \\
\operatorname{speed}(\mathrm{m} / \mathrm{s})\end{array}$ & $\begin{array}{l}\text { Feed rate } \\
(\mathrm{m} / \mathrm{min})\end{array}$ & $\begin{array}{l}\text { Grinding } \\
\text { depth } \\
(\mathrm{mm})\end{array}$ & $\begin{array}{c}\text { Test } \\
\text { value } F_{n} \\
(\mathrm{~N})\end{array}$ & $\begin{array}{c}\text { Test } \\
\text { value } \mathrm{F}_{\mathrm{t}} \\
(\mathrm{N})\end{array}$ & $\begin{array}{c}\text { Calculated } \\
\mathrm{F}_{\mathrm{n}}(\mathrm{N})\end{array}$ & $\begin{array}{c}\text { Calculated } \\
\mathrm{F}_{\mathrm{t}}(\mathrm{N})\end{array}$ & $\begin{array}{l}\text { Average } \\
\text { error } F_{n} \\
(\%)\end{array}$ & $\begin{array}{c}\text { Average } \\
\text { error } F_{t} \\
(\%)\end{array}$ \\
\hline Dry grinding & 30 & 10 & 0.01 & 71.8 & 24.1 & 71 & 19.6 & $1.1 \%$ & $18.6 \%$ \\
\hline at room & 30 & 10 & 0.02 & 143.6 & 36.2 & 134.0 & 34.0 & $6.9 \%$ & $6.1 \%$ \\
\hline temperature & 30 & 10 & 0.03 & 202.1 & 46.5 & 199.8 & 49.4 & $1.1 \%$ & $5.9 \%$ \\
\hline Traditional & 30 & 10 & 0.01 & 66.3 & 19.8 & 64.8 & 15.9 & $2.3 \%$ & $19.7 \%$ \\
\hline casting & 30 & 10 & 0.02 & 132.4 & 28.3 & 130.2 & 30.1 & $1.7 \%$ & $6.0 \%$ \\
\hline grinding & 30 & 10 & 0.03 & 194.6 & 46.0 & 206.4 & 46.6 & $5.7 \%$ & $1.3 \%$ \\
\hline Nanofluid & 30 & 10 & 0.01 & 58.2 & 14.2 & 62.4 & 12.8 & $7.1 \%$ & $9.8 \%$ \\
\hline casting & 30 & 10 & 0.02 & 116.7 & 24.7 & 122.1 & 25.2 & $4.4 \%$ & $2.0 \%$ \\
\hline grinding & 30 & 10 & 0.03 & 180.5 & 40.2 & 198.1 & 36.1 & $8.9 \%$ & $10.2 \%$ \\
\hline
\end{tabular}

Table 4 and Fig. 10 illustrate the calculation results of the grinding force components under three different grinding methods and different grinding depth conditions, i.e., chip forming force and friction force. If the grinding depth is fixed, the chip forming force is considerably lower than the friction force, which is less than $15 \%$ of the total grinding force. Thus, most of the grinding force is generated by friction, which causes a greater grinding force; the friction accounts for about $85 \%$ of the entire grinding force, and thus, a large amount of heat is generated during the grinding process. The generated heat is not dissipated in time, which causes a large amount of heat to be transferred to the workpiece. This causes burns on the processed workpiece. Because of the normal grinding force component (Fig. 10.a), the ratio of $\mathrm{F}^{\prime}{ }_{n c} / \mathrm{F}^{\prime}{ }_{n}$ slowly increases as the grinding depth $a_{p}$ increases, and the ratio of $F^{\prime}{ }_{n s} / F_{n}^{\prime}$ continues to decrease. The result of the tangential grinding force component (Fig. 10.b) and the result of the normal grinding force component (Fig. 
10.a) have the same changing trend. This phenomenon may be attributed to the above-mentioned crystal grain shedding and fracture behavior. Although it will shorten the service life of the grinding wheel, this phenomenon may result in a self-sharpening effect of the alumina grinding wheel.

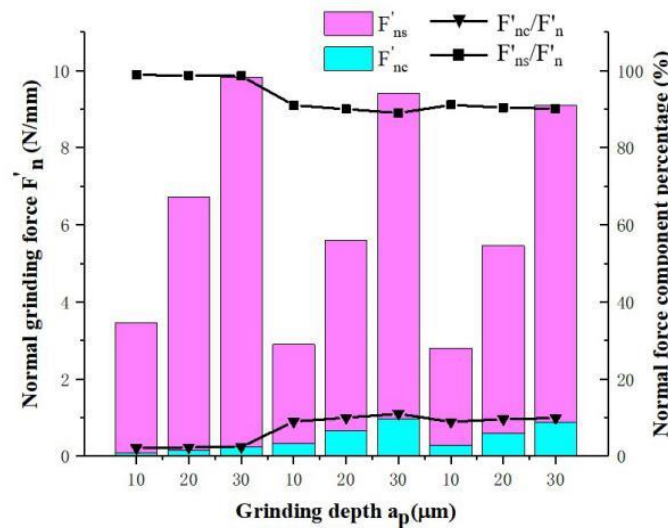

Dry grinding Casting grinding Nanocasting grinding

(a)

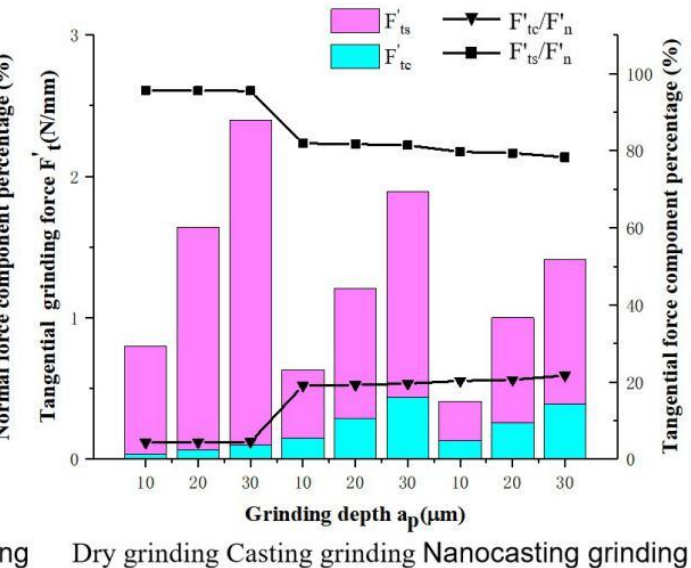

(b)

Fig. 10. Grinding force components under three different grinding methods and different grinding depths: (a) normal chip forming force and friction force, (b) tangential chip forming force and friction force.

\section{Conclusions}

In this study, three different grinding methods - normal temperature dry grinding, traditional pouring grinding, and nanofluid pouring grinding - were used to perform grinding experiments on $12 \mathrm{Cr} 2 \mathrm{Ni4A}$ steel. The workpieces after grinding were comprehensively studied. The main conclusions are as follows:

(1) The grinding force increases in the following order: nanofluid pouring grinding, traditional pouring grinding, and normal temperature dry grinding. The normal grinding force of nanofluid pouring grinding is higher than that of normal temperature dry grinding. The maximum grinding force is reduced by $19.2 \%$, and the tangential grinding force of nanofluid pouring grinding is lower than that of dry grinding at room temperature by up to $25.0 \%$.

(2) With an increase in grinding depth, the surface roughness of nanofluid casting grinding workpiece is lower than that of traditional casting grinding and normal temperature dry grinding; the surface roughness is reduced by $19.1 \%$ at the highest as observed via scanning electron microscopy. The surface defects of the nanofluid casting grinding workpiece were far lower than the surface defects of the normal temperature dry grinding and the traditional casting grinding (workpiece material overlap, surface cavity, tearing of workpiece material, and adhesion of metal fragments).

(3) Through the analysis of the micro-hardness distribution map, the softening layer of the workpiece under normal temperature dry grinding is $\sim 100 \mu \mathrm{m}$, the softening layer of the workpiece in traditional casting grinding is $\sim 40 \mu \mathrm{m}$, and the subsurface of the workpiece is measured by the scanning electron microscope. The observations show that the workpieces of normal temperature dry grinding have tempering burns; the highest affected layer is $\sim 98 \mu \mathrm{m}$; the workpieces of traditional casting grinding have secondary quenching burns, and the highest 
affected layers is $\sim 35 \mu \mathrm{m}$. The secondary quenching burns show subsurface defects (cavities).

(4) Through the analysis of the workpiece surface/subsurface after normal temperature dry grinding, traditional pouring grinding, and nanofluid pouring grinding, the surface quality of nanofluid pouring grinding can be concluded to be better than that of normal temperature dry grinding. The surface quality of the workpiece in grinding and traditional casting grinding was compared, and the results indicated that the sub-surface quality after nanofluid casting grinding has no burns, and there are tempering burns and secondary quenching burns in normal temperature dry grinding and traditional casting grinding; nanofluid casting grinding can improve the surface quality of workpieces and reduce grinding burns.

\title{
Ethical Approval
}

This article does not contain any studies with human participants or animals performed by any of the authors.

\section{Consent to Participate}

Not applicable.

\section{Consent to publish}

The authors consent to publish this article

\author{
Affiliations \\ Engineering Training Center, Xiangtan University, Xiangtan, 411105, Hunan, China \\ Gaofeng Zhang \\ School of Mechanical Engineering, Xiangtan University, Xiangtan, 411105, Hunan, China \\ Dejing Luo, Gaocan Wu, Da Liu, Jiakun Wang, Xin Deng, Jianbo Cai
}

\section{Corresponding author}

Correspondence to Gaofeng Zhang.

E-mail address: zgfxu@xtu.edu.cn

\section{Contributions}

Gaofeng Zhang proposed the idea of nanofluid casting grinding and presented the main research ideas. Dejing Luo conducted various theoretical studies, designed experiments, analyzed the results, and wrote literature. Gaocan Wu, JiaKun Wang, Da Liu, Xin Deng, and Jianbo Cai mainly participated in the experimental work.

\section{Funding}

This work was supported by the National Natural Science Foundation of China (Grant Nos.51775469, 91860133). 


\section{Declaration of conflicting interests}

The author(s) declared no potential conflicts of interest with respect to the research, authorship, and/or publication of this article.

\section{Data availability}

All data generated or analyzed during this study are included in this article.

\section{References}

1. Rowe WB (2009) Chapter 1 - Introduction. In: Rowe WB (ed) Principles of Modern Grinding Technology. William Andrew Publishing, Boston, pp 1-14

2. Brinksmeier E, Mutlugünes Y, Klocke F, et al (2010) Ultra-precision grinding. CIRP Ann Manuf Technol 59:652-671. https://doi.org/10.1016/j.cirp.2010.05.001

3. Mishra A, Prasad T (1985) Residual stresses due to a moving heat source. Int J Mech Sci 27:571-581. https://doi.org/https://doi.org/10.1016/0020-7403(85)90073-6

4. Brinksmeier E, Cammett JT, König W, et al (1982) Residual Stresses — Measurement and Causes in Machining Processes. CIRP Ann 31:491-510. https://doi.org/https://doi.org/10.1016/S0007-8506(07)60172-3

5. Santa-Aho S, Vippola M, Sorsa A, et al (2012) Development of Barkhausen noise calibration blocks for reliable grinding burn detection. J Mater Process Technol 212:408-416. https://doi.org/10.1016/j.jmatprotec.2011.10.003

6. Wei P, Zhou H, Liu H, et al (2019) Modeling of contact fatigue damage behavior of a wind turbine carburized gear considering its mechanical properties and microstructure gradients. Int J Mech Sci 156:283-296. https://doi.org/10.1016/j.ijmecsci.2019.04.004

7. Javaroni RL, Lopes JC, Diniz AE, et al (2020) Improvement in the grinding process using the MQL technique with cooled wheel cleaning jet. Tribol Int 152: https://doi.org/10.1016/j.triboint.2020.106512

8. Pande SJ, Lal GK (1976) Wheel wear in dry surface grinding. Int J Mach Tool Des Res 16:179-186. https://doi.org/https://doi.org/10.1016/0020-7357(76)90003-2

9. Verma N, ManojKumar K, Ghosh A (2017) Characteristics of aerosol produced by an internal-mix nozzle and its influence on force, residual stress and surface finish in SQCL grinding. J Mater Process Technol 240:223-232. https://doi.org/10.1016/j.jmatprotec.2016.09.014

10. Wu C, Cao S, Zhao YJ, et al (2021) Preheating assisted wire EDM of semi-conductive CFRPs: Principle and anisotropy. J Mater Process Technol 288:116915. https://doi.org/10.1016/j.jmatprotec.2020.116915

11. Paul S, Dhar NR, Chattopadhyay AB (2001) Beneficial effects of cryogenic cooling over dry and wet machining on tool wear and surface finish in turning AISI 1060 steel. J Mater Process Technol 116:44-48. https://doi.org/10.1016/S0924-0136(01)00839-1

12. Ekinovic S, Prcanovic H, Begovic E (2015) Investigation of Influence of MQL Machining Parameters on Cutting Forces during MQL Turning of Carbon Steel St52-3. Procedia Eng 
132:608-614. https://doi.org/10.1016/j.proeng.2015.12.538

13. Bhatt Y, Ghuman K, Dhir A (2020) Sustainable manufacturing. Bibliometrics and content analysis. J Clean Prod 260:120988. https://doi.org/10.1016/j.jclepro.2020.120988

14. Shen B, Shih AJ (2009) Minimum quantity lubrication (MQL) grinding using vitrified cbn wheels. Trans North Am Manuf Res Inst SME 37:129-136

15. Sezer N, Koç M (2018) Stabilization of the aqueous dispersion of carbon nanotubes using different approaches. Therm Sci Eng Prog 8:411-417. https://doi.org/10.1016/j.tsep.2018.09.011

16. Liu Q, Chen X, Gindy N (2007) Assessment of Al2O3 and superabrasive wheels in nickel-based alloy grinding. Int J Adv Manuf Technol 33:940-951. https://doi.org/10.1007/s00170-006-0519-1

17. Godino L, Pombo I, Sanchez JA, Alvarez J (2018) On the development and evolution of wear flats in microcrystalline sintered alumina grinding wheels. J Manuf Process 32:494-505. https://doi.org/10.1016/j.jmapro.2018.03.023

18. Ben Fathallah B, Ben Fredj N, Sidhom H, et al (2009) Effects of abrasive type cooling mode and peripheral grinding wheel speed on the AISI D2 steel ground surface integrity. Int J Mach Tools Manuf 49:261-272. https://doi.org/10.1016/j.ijmachtools.2008.10.005

19. Ghosh S, Chattopadhyay AB, Paul S (2008) Modelling of specific energy requirement during high-efficiency deep grinding. Int J Mach Tools Manuf 48:1242-1253. https://doi.org/10.1016/j.ijmachtools.2008.03.008

20. Li HN, Yu TB, Wang ZX, et al (2017) Detailed modeling of cutting forces in grinding process considering variable stages of grain-workpiece micro interactions. Int J Mech Sci 126:319-339. https://doi.org/10.1016/j.ijmecsci.2016.11.016

21. Rowe WB (2014) 2 - Basic Material Removal. In: Rowe WB (ed) Principles of Modern Grinding Technology (Second Edition), Second Edi. William Andrew Publishing, Oxford, pp $15-33$

22. Agarwal S, Rao PV (2013) Predictive modeling of force and power based on a new analytical undeformed chip thickness model in ceramic grinding. Int J Mach Tools Manuf 65:68-78. https://doi.org/10.1016/j.ijmachtools.2012.10.006

23. Thakur A, Gangopadhyay S (2016) State-of-the-art in surface integrity in machining of nickel-based super alloys. Int J Mach Tools Manuf 100:25-54. https://doi.org/10.1016/j.ijmachtools.2015.10.001

24. Lichun L, Jizai F, Peklenik J (1980) A Study of Grinding Force Mathematical Model. CIRP Ann 29:245-249. https://doi.org/https://doi.org/10.1016/S0007-8506(07)61330-4

25. Yao C, Wang T, Xiao W, et al (2014) Experimental study on grinding force and grinding temperature of Aermet 100 steel in surface grinding. J Mater Process Technol 214:2191-2199. https://doi.org/10.1016/j.jmatprotec.2014.04.013 


\section{Figures}
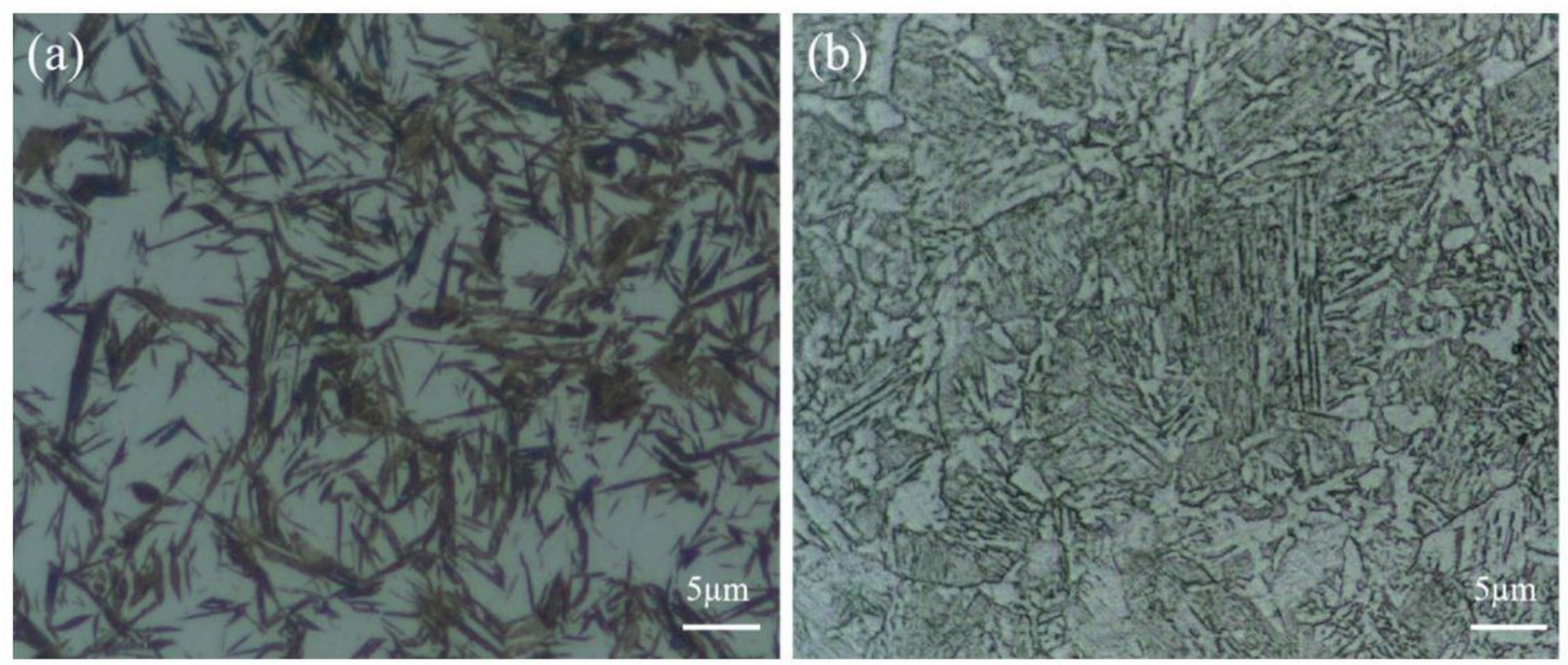

\section{Figure 1}

Microstructure of $12 \mathrm{Cr} 2 \mathrm{Ni} 4 \mathrm{~A}$ steel includes (a) carburized and (b) non-carburized areas. 

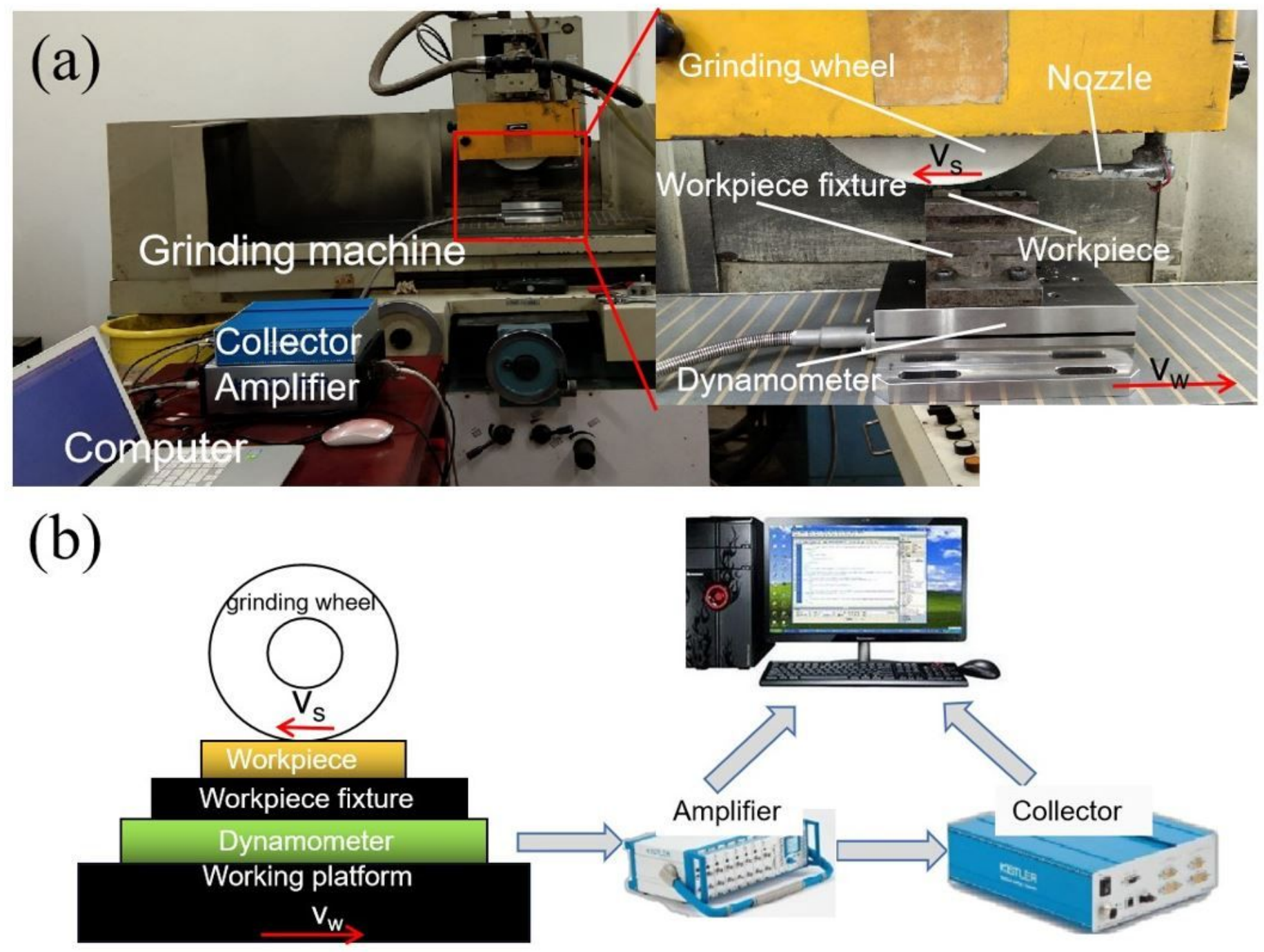

Figure 2

(a) Experimental device, (b) schematic of grinding force measurement. 
(a)

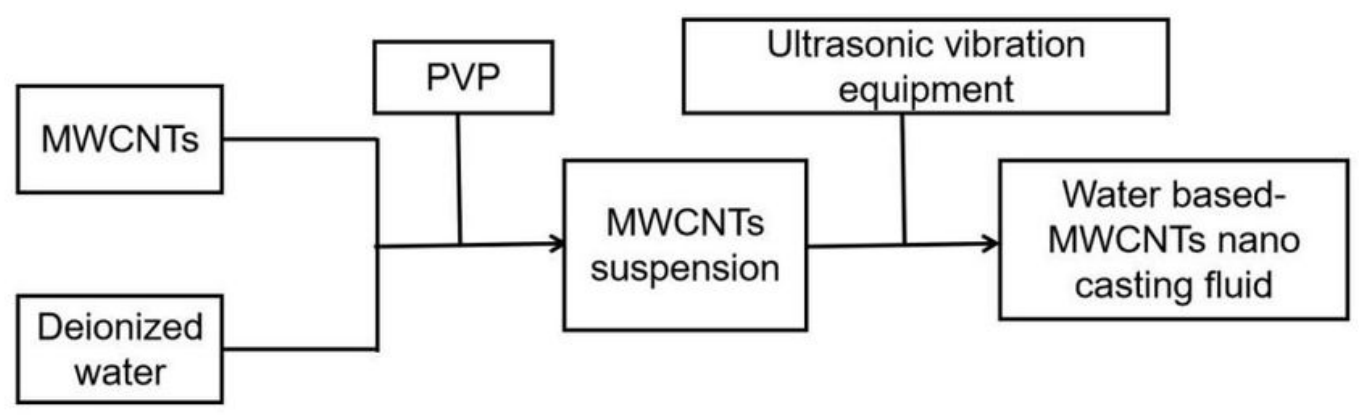

(b)

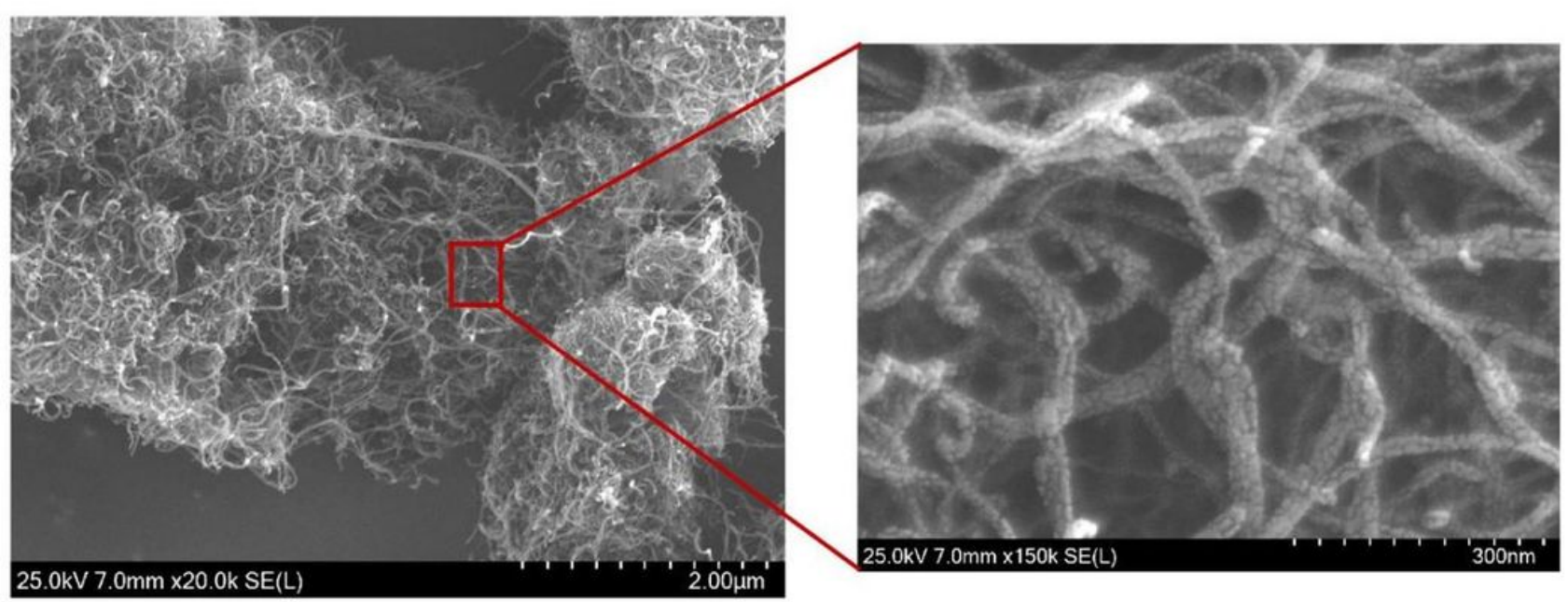

\section{Figure 3}

(a) Process flow chart of water-based nanofluid; (b) SEM image of MWCNTs.
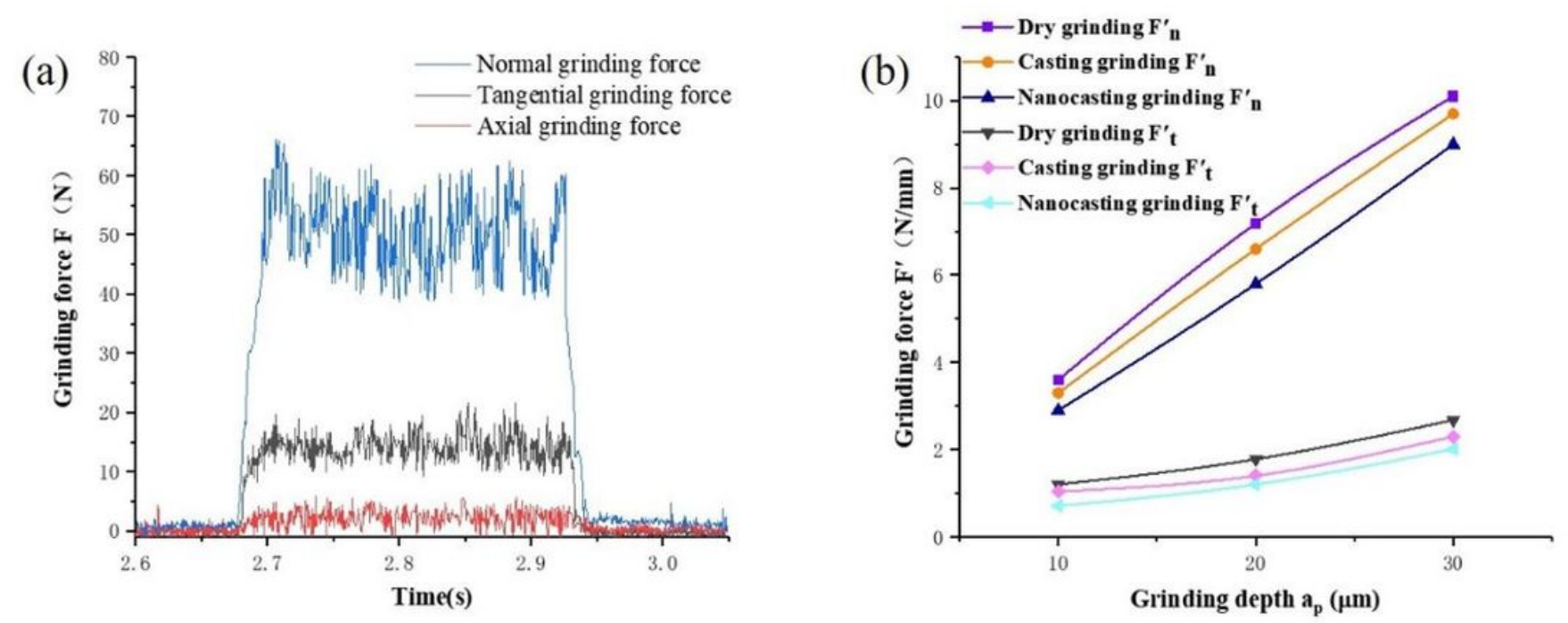

Figure 4

(a) Grinding force measured by nanofluid pouring grinding ( $v s=30 \mathrm{~m} / \mathrm{s}, \mathrm{vw}=10 \mathrm{~m} / \mathrm{min}$, ap = $10 \mu \mathrm{m})$; (b) Grinding force per unit width $\mathrm{F}^{\prime}$ varies with grinding depth ap. 

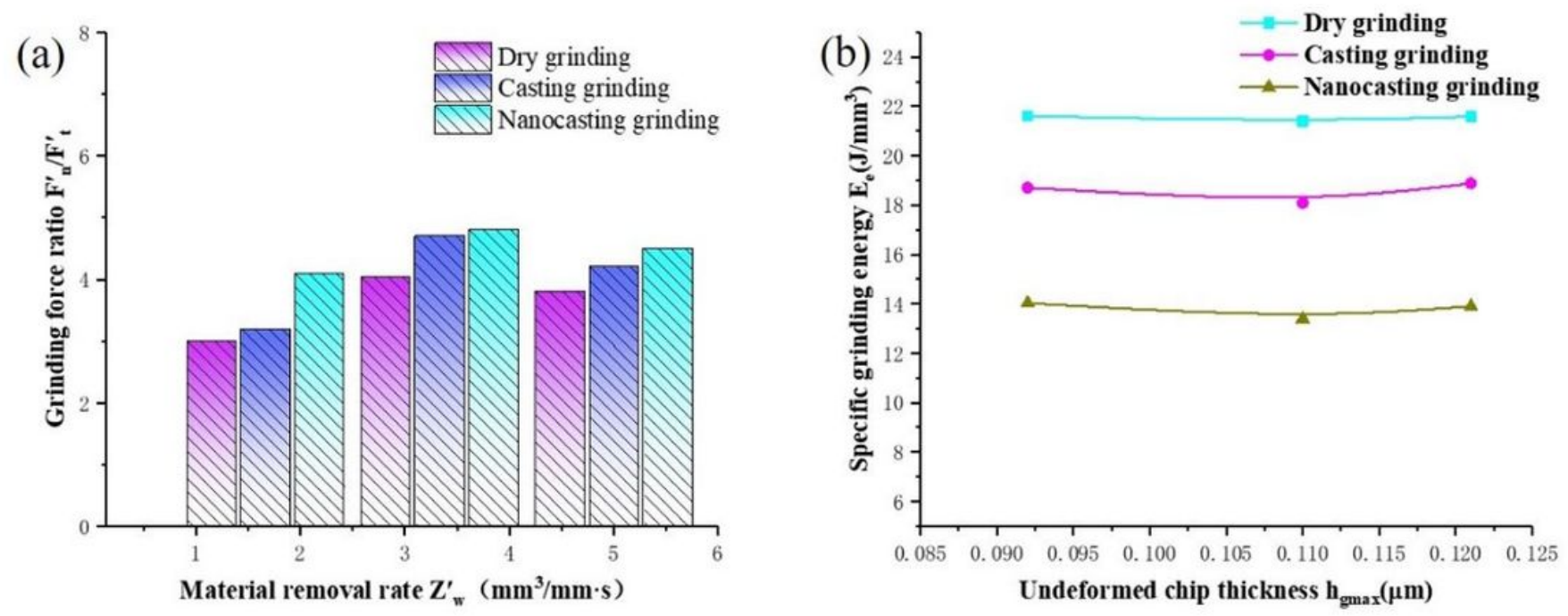

Figure 5

(a) The force ratio changes with the material removal rate; (b) specific grinding energy change with the maximum undeformed chip thickness. 


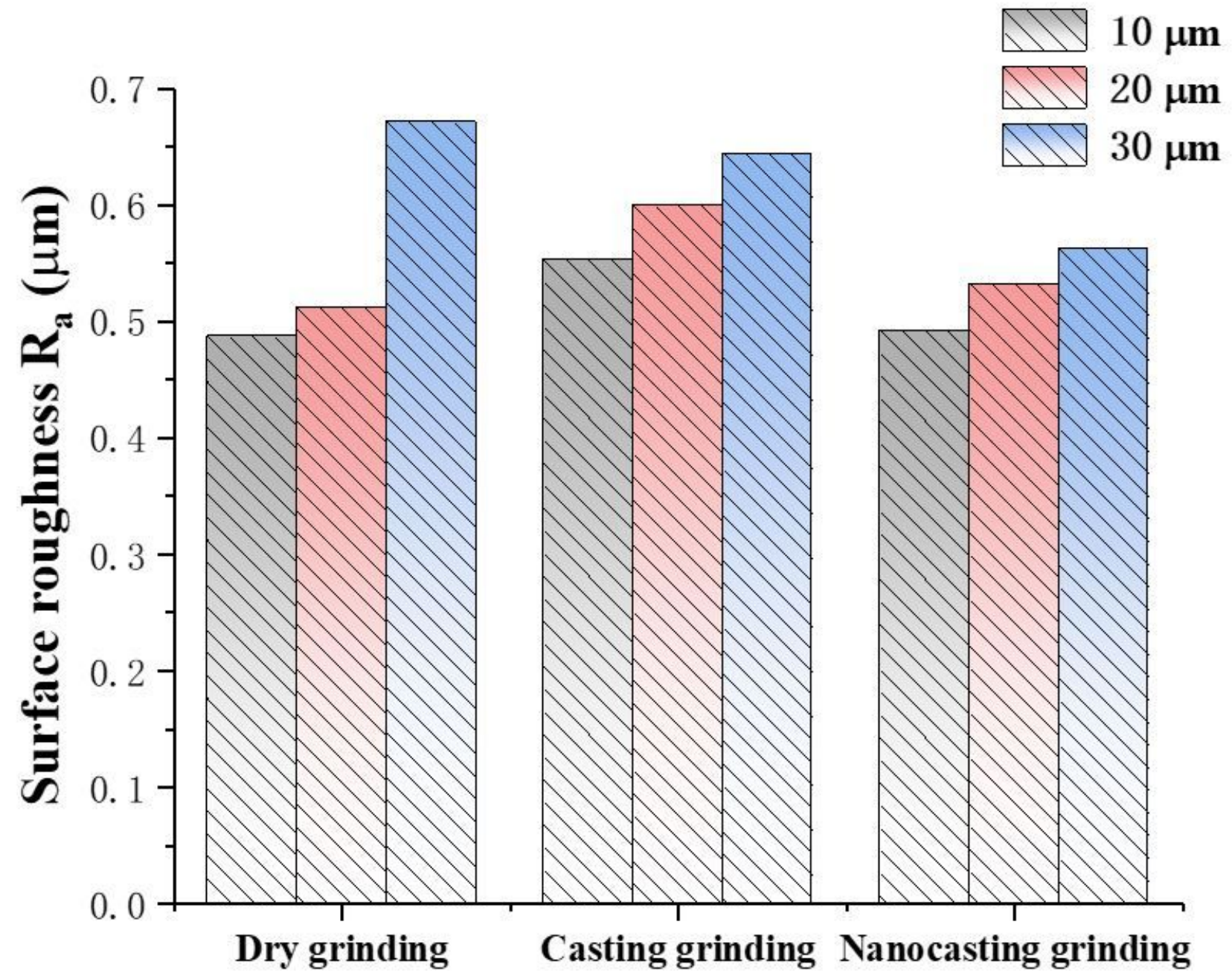

Figure 6

Surface roughness of workpieces with different grinding depths in three different grinding methods. 

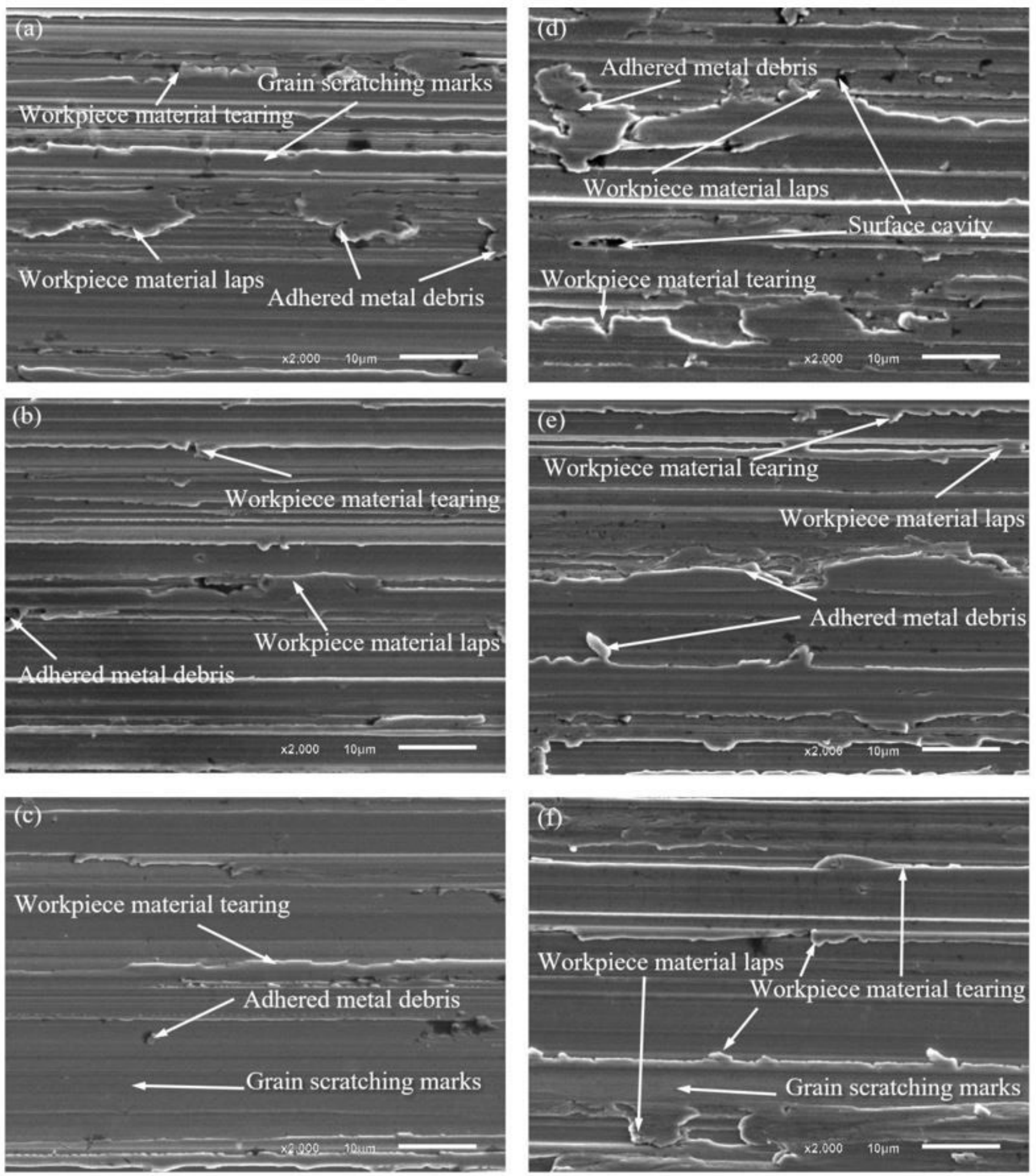

\section{Figure 7}

SEM image of the machined surface. (a) Dry grinding at room temperature, (b) Traditional pouring grinding, (c) Nanofluid pouring grinding ( $v s=30 \mathrm{~m} / \mathrm{s}, \mathrm{vw}=10 \mathrm{~m} / \mathrm{min}, \mathrm{ap}=20 \mu \mathrm{m}$ ) and (d) normal temperature dry grinding, (e) traditional pouring grinding, (f) nanofluid pouring grinding ( $v s=30 \mathrm{~m} / \mathrm{s}$, vw $=10 \mathrm{~m} / \mathrm{min}, \mathrm{ap}=30 \mu \mathrm{m})$. 
(a)

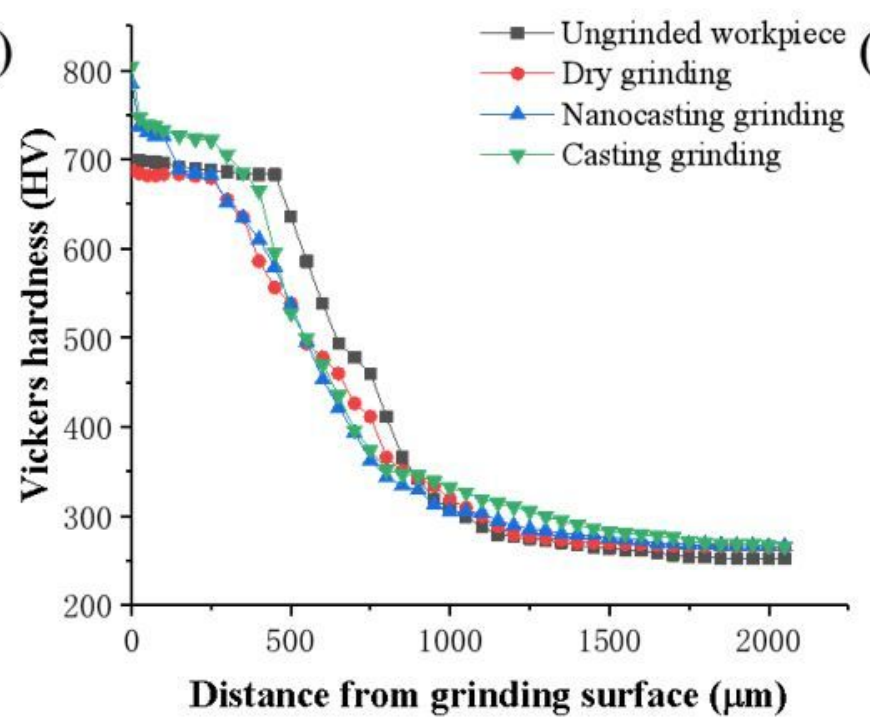

(b)

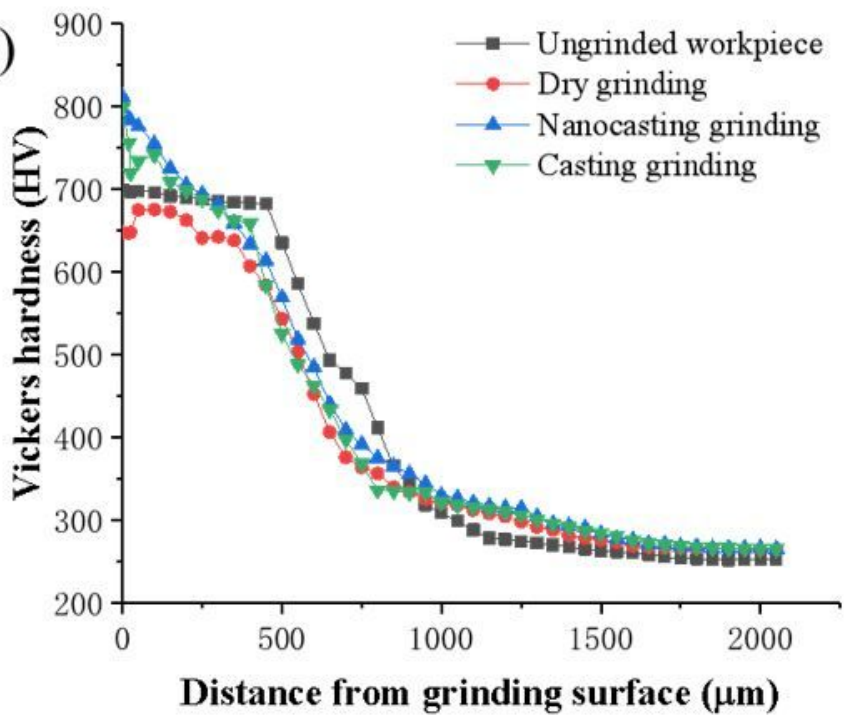

- Ungrinded workpiece

$\longrightarrow$ Dry grinding

^- Nanocasting grinding

$\rightarrow-$ Casting grinding

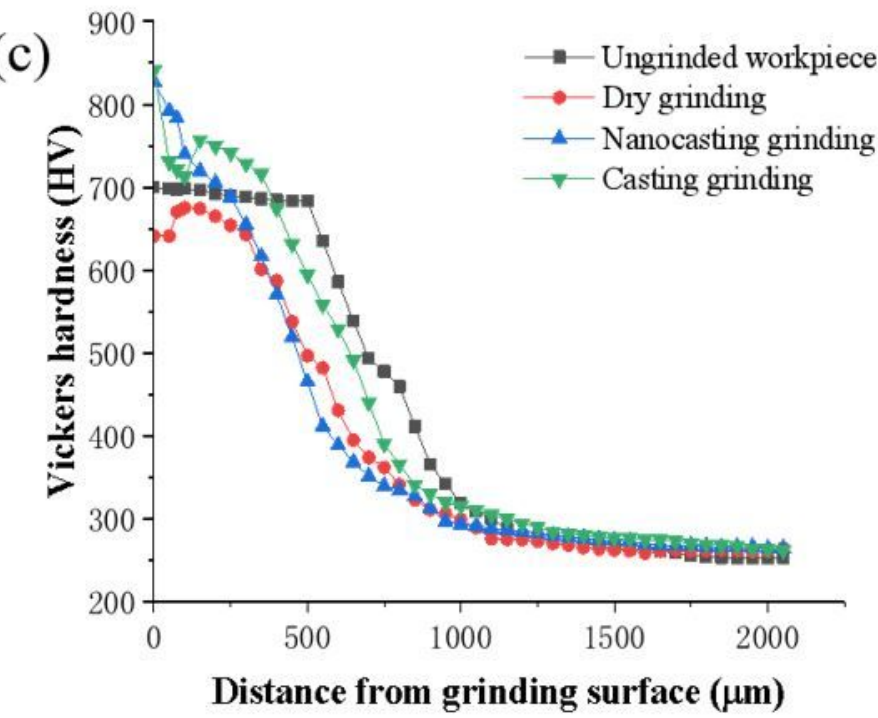

\section{Figure 8}

Microhardness change of the cross section of the workpiece; (a) vs $=30 \mathrm{~m} / \mathrm{s}, \mathrm{vw}=10 \mathrm{~m} / \mathrm{min}, \mathrm{ap}=10 \mu \mathrm{m}$, (b) $v s=30 \mathrm{~m} / \mathrm{s}, v w=10 \mathrm{~m} / \mathrm{min}$, ap $=20 \mu \mathrm{m}$, (c) $v s=30 \mathrm{~m} / \mathrm{s}, \mathrm{vw}=10 \mathrm{~m} / \mathrm{min}$, ap $=30 \mu \mathrm{m}$. 
(a)

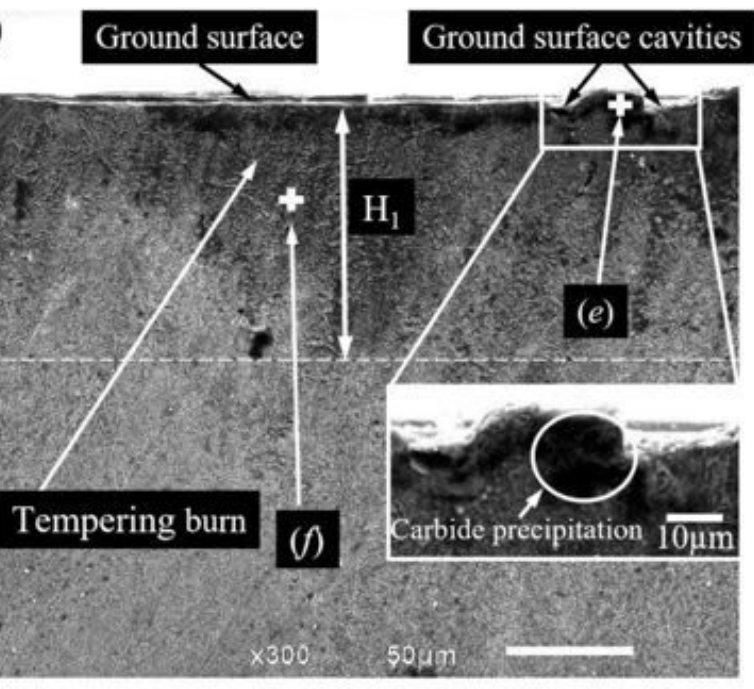

(c)

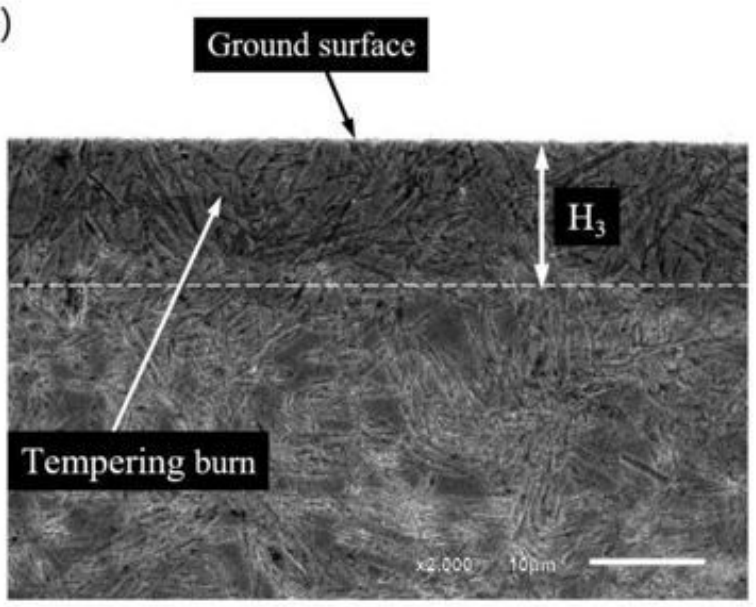

(e)

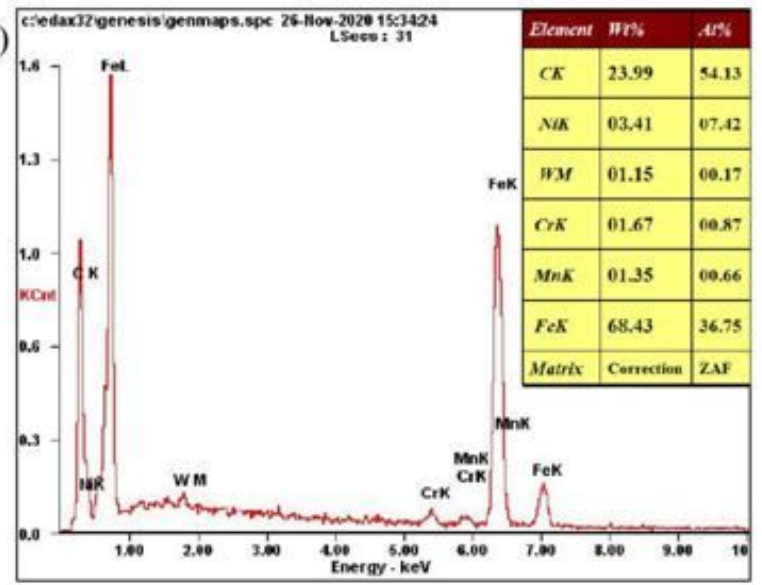

(b) Ground surface Ground surface cavities

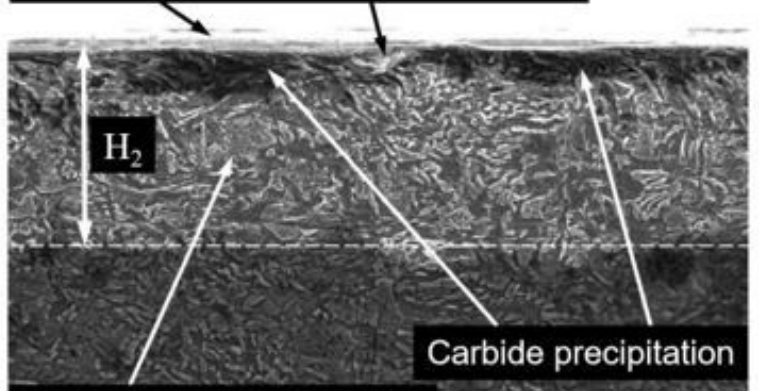

Secondary quenching burn

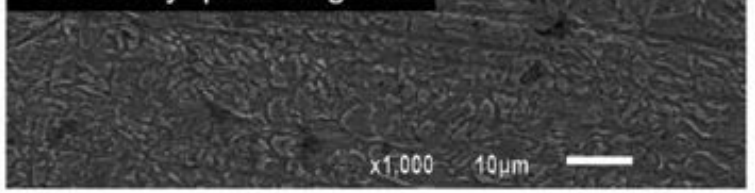

(d)

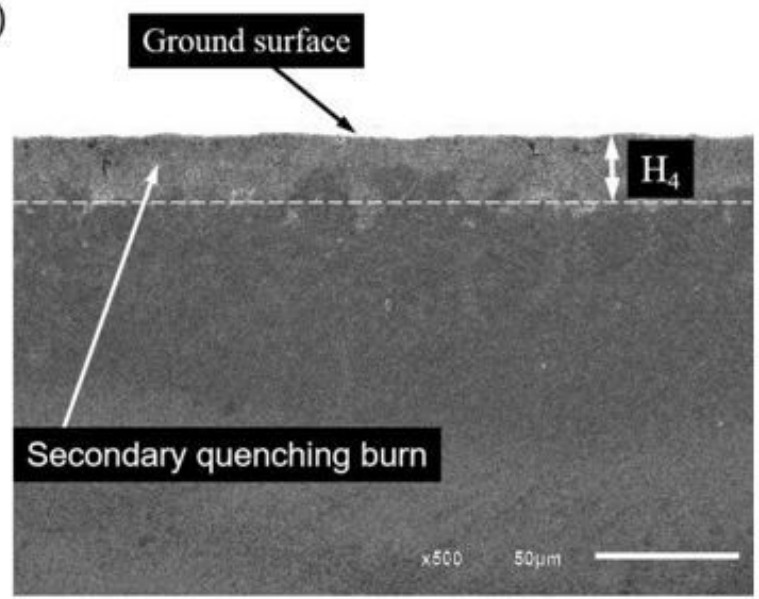

(f)

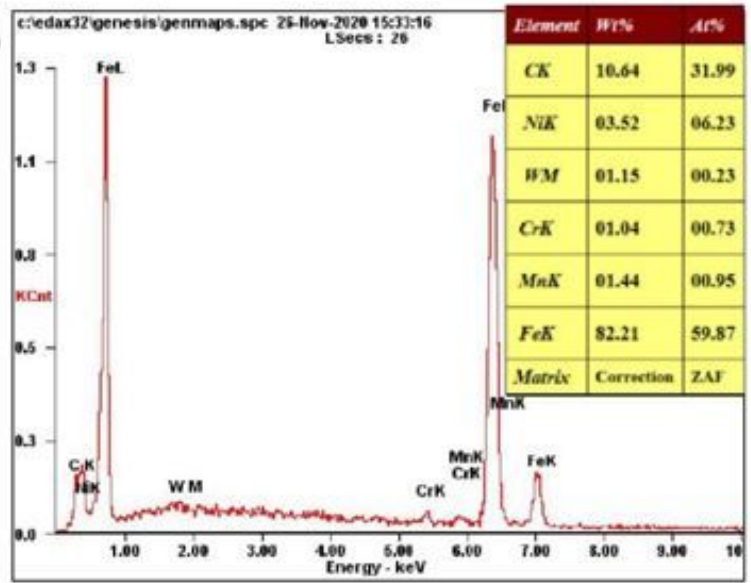

\section{Figure 9}

Scanning electron micrograph and energy spectrum of the subsurface of the workpiece (a) Dry grinding at room temperature (vs $=30 \mathrm{~m} / \mathrm{s}, \mathrm{vw}=10 \mathrm{~m} / \mathrm{min}, \mathrm{ap}=30 \mu \mathrm{m})$, (b) Traditional pouring grinding ( $\mathrm{vs}=30$ $\mathrm{m} / \mathrm{s}, \mathrm{vw}=10 \mathrm{~m} / \mathrm{min}, \mathrm{ap}=30 \mu \mathrm{m}$ ), (c) Dry grinding at room temperature (vs $=30 \mathrm{~m} / \mathrm{s}$, vw $=10 \mathrm{~m} / \mathrm{min}$, ap $=20 \mu \mathrm{m})$, (d) Traditional pouring grinding ( $v s=30 \mathrm{~m} / \mathrm{s}, \mathrm{vw}=10 \mathrm{~m} / \mathrm{min}$, ap = $20 \mu \mathrm{m})$, (e) Point e energy spectrum, (f) Point f energy spectrum. 


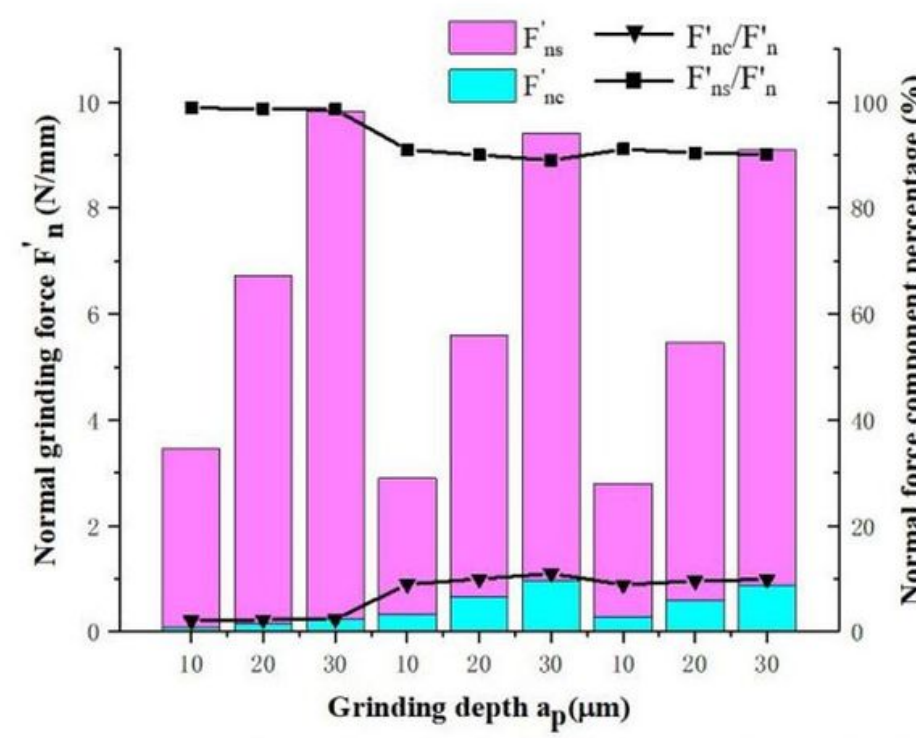

Dry grinding Casting grinding Nanocasting grinding

(a)

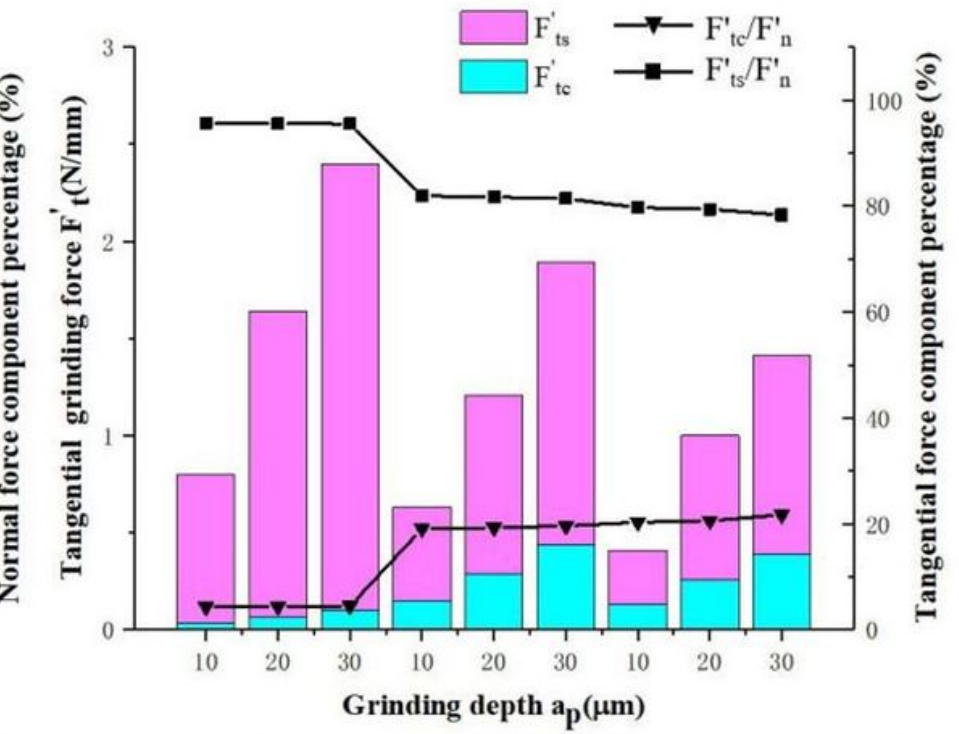

Dry grinding Casting grinding Nanocasting grinding

(b)

\section{Figure 10}

Grinding force components under three different grinding methods and different grinding depths: (a) normal chip forming force and friction force, (b) tangential chip forming force and friction force.

\section{Supplementary Files}

This is a list of supplementary files associated with this preprint. Click to download.

- LanguageEditingCertificate.pdf 